\title{
. \\ Zinc Status Index (ZSI) for Quantification of Zinc Physiological Status
}

\author{
Jacquelyn Cheng ${ }^{1}$, Haim Bar ${ }^{2}$ and Elad Tako ${ }^{1, *}$ \\ 1 Department of Food Science, Cornell University, Stocking Hall, Ithaca, NY 14853, USA; jyc53@cornell.edu \\ 2 Department of Statistics, University of Connecticut, Philip E. Austin Building, Storrs, CT 06269, USA; \\ haim.bar@uconn.edu \\ * Correspondence: et79@cornell.edu; Tel.: +1-607-255-0884
}

check for

updates

Citation: Cheng, J.; Bar, H.; Tako, E. Zinc Status Index (ZSI) for Quantification of Zinc Physiological Status. Nutrients 2021, 13, 3399. https://doi.org/10.3390/nu13103399

Academic Editor: Roberto Iacone

Received: 27 August 2021

Accepted: 26 September 2021

Published: 27 September 2021

Publisher's Note: MDPI stays neutral with regard to jurisdictional claims in published maps and institutional affiliations.

Copyright: (c) 2021 by the authors. Licensee MDPI, Basel, Switzerland. This article is an open access article distributed under the terms and conditions of the Creative Commons Attribution (CC BY) license (https:// creativecommons.org/licenses/by/ $4.0 /)$.

\begin{abstract}
Zinc (Zn) deficiency is estimated to affect over one billion (17\%) of the world's population Zn plays a key role in various cellular processes such as differentiation, apoptosis, and proliferation, and is used for vital biochemical and structural processes in the body. Widely used biomarkers of $\mathrm{Zn}$ status include plasma, whole blood, and urine $\mathrm{Zn}$, which decrease in severe Zn deficiency; however, accurate assessment of $\mathrm{Zn}$ status, especially in mild to moderate deficiency, is difficult, as studies with these biomarkers are often contradictory and inconsistent. Thus, sensitive and specific biological markers of $\mathrm{Zn}$ physiological status are still needed. In this communication, we provide the $\mathrm{Zn}$ status index (ZSI) concept, which consists of a three-pillar formula: (1) the LA:DGLA ratio, (2) mRNA gene expression of Zn-related proteins, and (3) gut microbiome profiling to provide a clear assessment of $\mathrm{Zn}$ physiological status and degree of $\mathrm{Zn}$ deficiency with respect to assessing dietary $\mathrm{Zn}$ manipulation. Analysis of five selected studies found that with lower dietary $\mathrm{Zn}$ intake, erythrocyte LA:DGLA ratio increased, mRNA gene expression of Zn-related proteins in duodenal and liver tissues was altered, and gut microbiota populations differed, where the ZSI, a statistical model trained on data from these studies, was built to give an accurate estimation of Zn physiological status. However, the ZSI needs to be tested and refined further to determine its full potential.
\end{abstract}

Keywords: zinc biomarker; microbiome; LA:DGLA; $\Delta 6$-desaturase; zinc deficiency; zinc transporters

\section{Introduction}

Over one billion people worldwide (17\% of the global population) suffer from dietary zinc (Zn) deficiency [1]. Zn is vital for numerous physiological and metabolic processes and plays a key role in various cellular processes such as differentiation, apoptosis, and proliferation [2]. $\mathrm{Zn}$ is a required cofactor for the function of over 300 different enzymes in the human body and approximately $10 \%$ of all human proteins presumably bind $\mathrm{Zn}$ in vivo [3,4]. Consequently, $\mathrm{Zn}$ has been implicated in key functions in the nervous, reproductive, and immune systems, and plays a central role in growth and development, where Zn inadequacy has been associated with poor growth, depressed immune function, increased vulnerability to and severity of infection, adverse outcomes of pregnancy, and neurobehavioral abnormalities $[2,5,6]$. As deficiency of $\mathrm{Zn}$ has been linked to severe health consequences, it is a major cause of early childhood morbidity and mortality in developing nations [7].

In the past decades, there has been a significant increase in the understanding of $\mathrm{Zn}$ homeostasis; however, an accurate assessment tool for $\mathrm{Zn}$ status remains elusive. Currently, there is no universally accepted single measure to assess $\mathrm{Zn}$ status. Widely used biomarkers of Zn status include plasma, whole blood, and urine $\mathrm{Zn}$, which decrease in severe $\mathrm{Zn}$ deficiency; however, accurate assessment of $\mathrm{Zn}$ status, especially in mild to moderate deficiency, is difficult, as findings from studies with these biomarkers are often contradictory and inconsistent [8]. The World Health Organization (WHO) has estimated that one-third of the global population is at risk for $\mathrm{Zn}$ deficiency based on the calculated proportion of individuals with intakes below country-level daily $\mathrm{Zn}$ requirements $[9,10]$. 
To recognize $\mathrm{Zn}$ deficiency in its early states, the WHO has indicated a need to develop additional robust indicators of $\mathrm{Zn}$ status and to further expand on already known clinical markers. Emerging biomarkers of $\mathrm{Zn}$ status that require further investigation include Zn-dependent proteins, Zn kinetics, taste acuity, oxidative stress, and DNA integrity [11].

In recent years, evidence has suggested current biomarkers, such as plasma (or serum) $\mathrm{Zn}$, are not sensitive and specific enough to small changes in $\mathrm{Zn}$ nutrition due to the ubiquitous nature of $\mathrm{Zn}$ in human biological systems [11,12]. Previously, our group established the concept of the essential role of $\mathrm{Zn}$ for $\Delta 6$-desaturase activity, where we explored $\mathrm{Zn}$ status relative to erythrocyte $\Delta 6$-desaturation, the LA:DGLA (linoleic acid:dihomo- $\gamma$-linolenic acid) ratio. We evaluated and provided evidence that demonstrated the effectiveness of the LA:DGLA ratio as a sensitive biomarker for assessing $\mathrm{Zn}$ status, where a significant negative correlation was found between dietary $Z n$ intake and the LA:DGLA ratio [13]. Mild Zn deficiency has been shown to alter Zn transporter (ZIP and ZnT transporters) gene expression and brush border membrane enzyme activity ( $\Delta 6$-desaturase) in vivo [14-16]. Further, the intestinal microbial environment is crucial for $\mathrm{Zn}$ metabolism and is in turn influenced by inferior $\mathrm{Zn}$ status. Previous work has demonstrated that lack of dietary Zn deleteriously affects the composition of the intestinal microbial populations through reductions in taxonomic richness and diversity, decreases in beneficial short-chain fatty acid (SCFA) production, and changes in the metagenomic potential of the microbiota $[17,18]$. Given that these perturbations may serve as possible effectors of Zn deficiency physiological status by limiting Zn solubility and precluding the host from optimal Zn availability, it is critical to consider these factors in relation to $\mathrm{Zn}$ physiological status $[17,19]$.

Considering the complexity of $\mathrm{Zn}$ metabolism, establishing a panel of biochemical indices is necessary to reliably assess $\mathrm{Zn}$ status. We have further developed a $\mathrm{Zn}$ status index (ZSI), a three-pillar formula that consists of (1) the LA:DGLA ratio, (2) mRNA gene expression of $Z n$-related proteins, and (3) fecal microbiome profiling to provide a clear and accurate measurement of $\mathrm{Zn}$ physiological status. Our ZSI aims to improve the understanding of Zn nutrition, physiological status, and severity of potential deficiency, which will ultimately lead to effective dietary $\mathrm{Zn}$ interventions and medical outcomes $[13,18,20]$. In this manuscript, we will first review the literature that discusses the rationale behind the three pillars of the ZSI, and then discuss the development and usage of the ZSI.

\section{Review of Literature on the Three Pillars of the ZSI: LA:DGLA Ratio, Zn-Related Gene Expression, and Gut Microbiome Modulation}

Five selected studies (Reed et al., 2014; Reed et al., 2015; Knez et al., 2017; Reed et al., 2018; and Beasley et al., 2020) were analyzed for this communication $[13,17,18,20,21]$. These studies utilized diet-controlled experiments with differential $\mathrm{Zn}$ content and determined how differential dietary Zn could affect the combination of parameters used in the ZSI. Due to the paucity of data that examined the combination of the LA:DGLA ratio, Zn-related gene expression, and gut microbiome, all five studies discussed utilized the Gallus gallus in vivo model and were selected on the basis that the data were readily available (studies were conducted in the authors' lab). The Gallus gallus model has previously been used to assess mineral bioavailability due to its sensitivity to dietary manipulation of minerals, such as $\mathrm{Zn}$, and thus can serve as a model for dietary $\mathrm{Zn}$ bioavailability and absorption in humans [22-26]. There is also $>85 \%$ homology between human and Gallus gallus in intestinal genes responsible for the expression of BBM (brush border membrane) proteins involved with mineral absorption, such as Zn Transporter 1 (ZnT1) [27]. Additionally, the Gallus gallus model harbors a complex and active gut microbiome, with significant resemblance at the phylum level between the gut microbiota of Gallus gallus and humans, with Bacteroidetes, Firmicutes, Proteobacteria, and Actinobacteria representing the dominant bacterial phyla in both $[25,28,29]$. 


\subsection{Materials and Methods}

\subsubsection{Animal Model, Study Design, and Experimental Diets}

Cornish cross-fertile broiler chicken eggs were obtained from a commercial hatchery (Moyer's chicks, Quakertown, PA, USA). The eggs were incubated under optimal conditions at the Cornell University Animal Science poultry farm incubator until hatching [30]. Hatchlings were randomly distributed into two treatment groups based on body weight and sex to ensure equal distribution between groups. Chickens were housed in cages $\left(1 \mathrm{~m}^{2}\right)$ and provided ad libitum access to food and $\mathrm{H}_{2} \mathrm{O}$. Reed et al. (2014) and Reed et al. (2015) were conducted over the course of 4 weeks. Knez et al. (2017), Reed et al. (2018), and Beasley et al. (2020) were conducted over the course of 6 weeks. At the study conclusion, the animal subjects were euthanized by $\mathrm{CO}_{2}$ exposure, and the ceca, duodenum, and liver were quickly removed and stored in a $-80{ }^{\circ} \mathrm{C}$ freezer until analysis, as was previously described [13]. All animal protocols were approved by Cornell University Institutional Animal Care and Use Committee (IACUC \#2020-0077).

The NRC (Nation Research Council) recommendations and requirements for poultry were consulted to formulate diets that meet the nutrient requirements for the broiler [31]. In Reed et al. (2014) and Reed et al. (2015), the experimental diets (Zn-adequate control and $\mathrm{Zn}$-deficient groups) differed only in terms of supplemental Zn (as Zn carbonate) [13]. In Knez et al. (2017) and Reed et al. (2018), the wheat-based diets (standard and Zn-biofortified wheat) differed only in levels of Zn. In Beasley et al. (2020), the wheat-based diets (standard and nicotianamine enhanced $\mathrm{Zn}$ - and Fe-biofortified wheat) differed only in levels of $\mathrm{Zn}, \mathrm{Fe}$, and nicotianamine. In the Knez et al. (2017), Reed et al. (2018), and Beasley et al. (2020) studies, $\mathrm{Zn}, \mathrm{Fe}$, phytate, calcium, fatty acid, and protein concentrations were measured in the standard and biofortified wheat-based diets as previously described [13]. Further details on the diet preparation and diet composition can be found in the respective studies $[13,17,18,20,21]$.

\subsubsection{Blood Collection and Erythrocyte Fatty Acid Analysis}

Blood was collected weekly from the wing vein using micro-hematocrit heparinized capillary tubes (Fisher Scientific, Waltham, MA, USA) following an 8 h overnight fast. The blood samples were stored on ice until transportation within $4 \mathrm{~h}$ to the Tako Laboratory, where whole blood was fractionated by centrifuging at $\sim 2000 \times \mathrm{g}$ for 10-15 min at room temperature and stored in a $-80^{\circ} \mathrm{C}$ freezer until analysis. Fatty acid profile was determined via gas chromatography mass spectrometry after fatty acid extraction from blood erythrocytes and derivatization to fatty acid methyl esters with boron trifluoride in methanol. The method for erythrocyte fatty acid analysis was previously described [13,32-35].

\subsubsection{Determination of Serum, Nail, Feather, and Liver Zn Content}

Blood, nail, feather, and liver samples were collected on the final day of the experiment ( 1-2 g). Serum, nail, and feather Zn concentrations were determined by an inductively coupled argon-plasma/atomic emission spectrophotometer (ICAP 61E Thermal Jarrell Ash Trace Analyzer, Jarrell Ash Co., Franklin, MA, USA) following wet ashing as previously described $[13,21]$.

\subsubsection{Isolation of Total RNA}

Total RNA was extracted from $30 \mathrm{mg}$ of duodenal or liver tissue using a Qiagen RNeasy Mini Kit (Qiagen Inc., Germantown, MD, USA) according to the manufacturer's protocol. Total RNA was eluted in $50 \mu \mathrm{L}$ of RNase-free water. All steps were carried out under RNase-free conditions. RNA was quantified with a NanoDrop 2000 (ThermoFisher Scientific, Waltham, MA, USA) at $\mathrm{A}_{260 / 280}$. RNA was stored at $-80^{\circ} \mathrm{C}$ until use.

\subsubsection{Real-Time Polymerase Chain Reaction (RT-PCR)}

Primer design was conducted as previously published [36]. The sequence and primer description are shown in Table 1. cDNA was generated using a C1000 Touch thermocycler (Bio-Rad, Hercules, CA, USA) and a Promega-Improm-II Reverse Transcriptase Kit (Catalog 
\#A1250) $20 \mu \mathrm{L}$ reverse transcriptase reaction. The reverse transcriptase reaction consisted of $1 \mu \mathrm{g}$ total RNA template, $10 \mu \mathrm{M}$ random hexamer primers, and $2 \mathrm{mM}$ of oligo-dT primers. All reactions were performed under the following conditions: $94{ }^{\circ} \mathrm{C}$ for $5 \mathrm{~min}$, $60 \mathrm{~min}$ at $42^{\circ} \mathrm{C}, 70^{\circ} \mathrm{C}$ for $15 \mathrm{~min}$, and hold at $4{ }^{\circ} \mathrm{C}$. The concentration of cDNA obtained was determined with a NanoDrop 2000 at $A_{260 / 280}$ with an extinction coefficient of 33 for single-stranded DNA. RT-PCR was performed as previously published [21,37].

Table 1. The DNA sequences of primers used in this study: ZnT1, zinc transporter 1; ZnT5, zinc transporter 5; ZnT7, zinc transporter 7; ZIP1, zinc transport protein 1; ZIP4, zinc transport protein 4; ZIP6, zinc transport protein 6; ZIP9, zinc transport protein 9.

\begin{tabular}{|c|c|c|c|c|c|}
\hline Analyte & Organ & Forward Primer $\left(5^{\prime}-3^{\prime}\right)$ & Reverse Primer $\left(5^{\prime}-3^{\prime}\right)$ & $\begin{array}{l}\text { Base } \\
\text { Pair }\end{array}$ & GI Identifier \\
\hline ZnT1 & duodenum & GGTAACAGAGCTGCCTTAACT & GGTAACAGAGCTGCCTTAACT & 105 & 54109718 \\
\hline $\mathrm{ZnT5}$ & duodenum & TGGTTGGTATCTGTGCCTTTAG & GGCTGTGTCCATGGTAAGATT & 99 & 56555150 \\
\hline ZnT7 & duodenum & GGAAGATGTCAGGATGGTTCA & CGAAGGACAAATTGAGGCAAAG & 87 & 56555152 \\
\hline ZIP1 & duodenum & TGCCTCAGTTTCCСTCAC & GGCTCTTAAGGGCACTTCT & 144 & XM_015298606.1 \\
\hline ZIP4 & duodenum & TCTCCTTAGCAGACAATTGAG & GTGACAAACAAGTAGGCGAAAC & 95 & 107050877 \\
\hline ZIP6 & duodenum & GCTACTGGGTAATGGTGAAGAA & GCTGTGCCAGAACTGTAGAA & 99 & 66735072 \\
\hline ZIP9 & duodenum & CTAAGCAAGAGCAGCAAAGAAG & CATGAACTGTGGCAACGTAAAG & 100 & 237874618 \\
\hline$\Delta 6$-desaturase & liver & GGCGAAAGTCAGCCTATTGA & AGGTGGGAAGATGAGGAAGA & 93 & 261865208 \\
\hline $18 \mathrm{~S}$ & duodenum, liver & GCAAGACGAACTAAAGCGAAAG & TCGGAACTACGACGGTATCT & 100 & 7262899 \\
\hline
\end{tabular}

\subsubsection{S rRNA Gene Amplification, Sequencing, and Analysis}

16S rRNA gene amplification, sequencing, and analysis were performed as previously described [16-18,20,29]. Microbial genomic DNA was extracted from cecal samples using the PowerSoil DNA isolation kit, as described by the manufacturer (MoBio Laboratories Ltd., Carlsbad, CA, USA). Bacterial 16S rRNA gene sequences were PCR-amplified from each sample using the 515F-806R primers for the V4 hypervariable region of the $16 \mathrm{~S}$ rRNA gene, including 12-base barcodes. $16 \mathrm{~S}$ rRNA gene sequence analysis was performed as previously described [17].

\subsubsection{Statistical Analysis}

Dissimilarities among experimental groups were tested by ANOVA using SAS software (SAS Institute Inc. Cary, NC, USA) with Tukey's method for adjustment for multiple testing. A threshold of adjusted- $p<0.05$ was considered statistically significant. Nonparametric factorial Kruskal-Wallis rank-sum tests were used to compare the relative abundance of distinct taxonomic units. Unweighted UniFrac was used to assess phylogenetic diversity. The Spearman's rank correlation was employed to assess significant associations between bacterial groups and biomarkers of Zn status. Multivariate Association with Linear Models (MaAsLin) was used to identify potential correlations between operational taxonomic unit (OTU) abundance and host phenotype. Significant $p$-values $(p<0.05)$ associated with microbial clades and functions identified by Linear discriminant analysis Effect Size (LEfSe) were corrected for multiple comparisons using the Benjamini and Hochberg false discovery rate (FDR) method.

\subsection{Results}

The five original papers selected and included for the ZSI were performed in the United States and the experimental model used was the Cornish Cross broiler (Gallus gallus) $[13,17,18,20,21]$.

All the studies were based on diets consisting of differing amounts of dietary $\mathrm{Zn}$. The Zn dosage varied between studies, as summarized in Table 2. One study (Beasley et al., 2020) evaluated nicotianamine-enhanced $\mathrm{Zn}$ - and Fe-biofortified wheat effects in the context of a complete diet composed of $80 \%$ wheat on the LA:DGLA ratio, Zn-related gene expression, and gut microbiota alterations (treatment groups are denoted as "biofortified" versus "control") [20]. Two papers evaluated the same Zn-biofortified wheat as part of a complete 
diet composed of 75\% wheat, with Knez et al. (2018) evaluating the LA:DGLA ratio and Zn-related gene expression, and Reed et al. (2018) evaluating gut microbiota alterations of the same study (treatment groups are denoted as "Low $\mathrm{Zn}$ " for the standard wheat control and "High Zn" for the Zn-biofortified wheat) [18,21]. Two papers evaluated chronic dietary Zn deficiency utilizing purified diets, with Reed et al. (2014) evaluating the LA:DGLA ratio and Zn-related gene expression, and Reed et al. (2015) evaluating gut microbiota alterations of the same study (treatment groups are denoted as "Zn adequate" and "Zn deficient") [13,17]. The characteristics and methods of the studies are described in Table 2.

Table 3 summarizes the main findings of the five selected studies with respect to parameters used for the ZSI, with the main results described in the following subsections.

\subsubsection{Zn Consumption}

$\mathrm{Zn}$ intakes were consistently higher in the Zn-adequate versus Zn-deficient groups in Reed et al. (2014) and Reed et al. (2015) [13,17]. For Knez et al. (2018) and Reed et al. (2018), $\mathrm{Zn}$ intakes were consistently lower in the low-Zn group versus the high-Zn group [18,21]. In Beasley et al. (2020), the biofortified group had lower Zn consumption than the control group over the course of the study (21.0 $\mathrm{mg}$ compared to $22.1 \mathrm{mg} \mathrm{Zn}$, respectively) [20].

\subsubsection{LA:DGLA Ratio}

Of the five studies included for the ZSI evaluation, three studies evaluated the erythrocyte LA:DGLA ratio. In Reed et al. (2014), the LA:DGLA was significantly decreased in the Zn-adequate group relative to the Zn-deficient group at weeks 1, 2, and 3, but not significantly different at week 4 [13]. In Knez et al. (2018), there was a significant decrease in the LA:DGLA ratio in subjects on the high $\mathrm{Zn}$ wheat-based diet at each timepoint (weeks $2,4,6$ ) [21]. In Beasley et al. (2020), in the biofortified group relative to the control group, the LA:DGLA ratio was significantly decreased at two weeks [20].

\subsubsection{Zn-Related Gene Expression}

Three of the five studies included for ZSI evaluated Zn-related gene expression. In Reed et al. (2014) and Knez et al. (2018), $\Delta 6$-desaturase gene expression was significantly altered in the experimental group with increased $\mathrm{Zn}$ consumption $[13,21]$. The gene expression of tested Zn transporters (ZnT1, ZnT5, ZnT7, ZIP4, ZIP6, ZIP9) was significantly downregulated in the high-Zn group compared to the low-Zn group in the Knez et al. (2018) study [21]. For the tested Zn transporters (ZnT1, ZnT5, ZnT7, ZIP6, ZIP9) in Reed et al. (2014), there were no significant changes in gene expression between the Zn-adequate and Zn-deficient groups [13]. There were no significant changes in Zn-related gene expression in Beasley et al. (2020) between the biofortified and control groups [20].

\subsubsection{Analysis of the Gut Microbiota}

Of the five studies included for ZSI evaluation, three studies evaluated gut (cecal) microbiota modulation. All three studies found changes in $\beta$-diversity, whereas two studies (Reed et al. (2015) and Beasley et al. (2020)) found changes in $\alpha$-diversity between the experimental and control groups [17,18,20]. At the phyla level, Reed et al. (2015) and Beasley et al. (2020) found increased Firmicutes and Proteobacteria relative abundance between the control and experimental groups [17,20]. In Reed et al. (2018), no significant changes were found at the phyla level between the high-Zn and low-Zn groups [18]. The studies that focused on biofortified wheat found changes in bacterial abundance at the genera level in Dorea spp. and Ruminococcus spp. between the biofortified and control groups $[18,20]$. In all three studies, $\mathrm{Zn}$ biofortification and/or $\mathrm{Zn}$ adequacy was found to be associated with increased SCFA production. Finally, metagenomic potential of the gut microbiota was found to be significantly altered in all three studies $[17,18,20]$. 
Table 2. Characteristics and methods of studies assessed for the ZSI: LA:DGLA, Zn-related gene expression, and Zn status effects on gut microbiota modulation.

\begin{tabular}{|c|c|c|c|c|c|c|c|c|}
\hline \multirow[b]{2}{*}{ Reference } & \multirow[b]{2}{*}{ Animal Model } & \multirow[b]{2}{*}{ Number of Subjects } & \multirow[b]{2}{*}{ Treatment or Intervention } & \multirow{2}{*}{$\begin{array}{l}\text { Duration } \\
\text { (Weeks) }\end{array}$} & \multicolumn{4}{|c|}{ Zn Status Measures } \\
\hline & & & & & $\begin{array}{c}\text { LA:DGLA } \\
\text { (Erythrocyte) }\end{array}$ & $\begin{array}{c}\text { Zn-Related Gene } \\
\text { Expression }\end{array}$ & $\begin{array}{c}\text { Gut Microbiota } \\
\text { Evaluation Method }\end{array}$ & $\begin{array}{c}\text { Other (Not } \\
\text { Included in ZSI) }\end{array}$ \\
\hline Beasley et al., 2020 [20] & $\begin{array}{l}\text { Cornish Cross broiler } \\
\text { (Gallus gallus) }\end{array}$ & $\begin{array}{c}30 \\
(\mathrm{n}=15 \text { per group })\end{array}$ & $\begin{array}{l}\text { Nicotianamine-enhanced Zn- } \\
\text { and Fe-biofortified wheat } \\
\text { (Triticum aestivum L.) }\end{array}$ & 6 & Yes & $\begin{array}{c}\text { ZnT1 } \\
\text { ZnT5 } \\
\text { ZnT7 } \\
\text { ZIP1 } \\
\text { ZIP4 } \\
\text { ZIP6 } \\
\text { ZIP9 } \\
\Delta 6 \text {-desaturase }\end{array}$ & $\begin{array}{l}\text { 16s rRNA gene } \\
\text { sequencing }\end{array}$ & $\begin{array}{c}\text { Serum } \\
\text { Liver } \\
\text { Nail } \\
\text { Feathers }\end{array}$ \\
\hline Knez et al., 2018 [21] & $\begin{array}{l}\text { Cornish Cross broiler } \\
\quad \text { (Gallus gallus) }\end{array}$ & $\begin{array}{c}30 \\
(\mathrm{n}=15 \text { per group })\end{array}$ & $\begin{array}{l}\text { Zn-biofortified wheat } \\
\text { (Triticum aestivum) }\end{array}$ & 6 & Yes & $\begin{array}{c}\text { ZnT1 } \\
\text { ZnT5 } \\
\text { ZnT7 } \\
\text { ZIP4 } \\
\text { ZIP6 } \\
\text { ZIP9 } \\
\text { 46-desaturase }\end{array}$ & N/A & $\begin{array}{l}\text { Serum } \\
\text { Nail } \\
\text { Feathers }\end{array}$ \\
\hline Reed et al., 2018 [18] & $\begin{array}{l}\text { Cornish Cross broiler } \\
\text { (Gallus gallus) }\end{array}$ & $\begin{array}{c}30 \\
(\mathrm{n}=15 \text { per group })\end{array}$ & $\begin{array}{l}\text { Zn-biofortified wheat } \\
\text { (Triticum aestivum) }\end{array}$ & 6 & Yes & $\begin{array}{c}\text { ZnT1 } \\
\text { ZnT5 } \\
\text { ZnT7 } \\
\text { ZIP4 } \\
\text { ZIP6 } \\
\text { ZIP9 } \\
\text { 46-desaturase }\end{array}$ & $\begin{array}{l}\text { 16s rRNA gene } \\
\text { sequencing }\end{array}$ & $\begin{array}{l}\text { Serum } \\
\text { Nail } \\
\text { Feathers }\end{array}$ \\
\hline Reed et al., 2015 [17] & $\begin{array}{l}\text { Cornish Cross broiler } \\
\text { (Gallus gallus) }\end{array}$ & $\begin{array}{c}24 \\
(\mathrm{n}=12 \text { per group) }\end{array}$ & $\begin{array}{l}\text { Zn-adequate control diet } \\
\text { versus Zn-deficient diet } \\
\text { (Zn carbonate as Zn source) }\end{array}$ & 4 & Yes & $\begin{array}{c}\text { ZnT1 } \\
\text { ZnT5 } \\
\text { ZnT7 } \\
\text { ZIP6 } \\
\text { ZIP9 } \\
\Delta \text { 6-desaturase }\end{array}$ & $\begin{array}{l}\text { 16s rRNA gene } \\
\text { sequencing }\end{array}$ & $\begin{array}{l}\text { Serum } \\
\text { Nail } \\
\text { Feathers }\end{array}$ \\
\hline Reed et al., 2014 [13] & $\begin{array}{l}\text { Cornish Cross broiler } \\
\text { (Gallus gallus) }\end{array}$ & $\begin{array}{c}24 \\
(\mathrm{n}=12 \text { per group) }\end{array}$ & $\begin{array}{l}\text { Zn-adequate control diet } \\
\text { versus Zn-deficient diet } \\
\text { (Zn carbonate as Zn source) }\end{array}$ & 4 & Yes & $\begin{array}{c}\text { ZnT1 } \\
\text { ZnT5 } \\
\text { ZnT7 } \\
\text { ZIP6 } \\
\text { ZIP9 } \\
\Delta 6 \text {-desaturase }\end{array}$ & $\mathrm{N} / \mathrm{A}$ & $\begin{array}{l}\text { Serum } \\
\text { Nail } \\
\text { Feathers }\end{array}$ \\
\hline
\end{tabular}


Table 3. Results of studies assessed for the ZSI: LA:DGLA, Zn-related gene expression, and Zn status effects on gut microbiota modulation.

\begin{tabular}{|c|c|c|c|c|c|}
\hline \multirow[b]{2}{*}{ Reference } & \multirow{2}{*}{$\begin{array}{c}\text { Zn Content } \\
(\mu \mathrm{g} \mathrm{Zn/g})\end{array}$} & \multicolumn{4}{|c|}{ Zn Status Measures } \\
\hline & & $\begin{array}{c}\text { LA:DGLA } \\
\text { (Erythrocyte) }\end{array}$ & Zn-Related Gene Expression & Gut Microbiota Modulation & Other (Not Included in ZSI) \\
\hline Beasley et al., 2020 [20] & $\begin{array}{l}\text { Control: } \\
16.6 \pm 0.06 \\
\text { (standard wheat) } \\
\text { Biofortified: } \\
19.2 \pm 0.03 \\
\text { (nicotianamine-enhanced Zn- } \\
\text { and Fe-biofortified wheat) }\end{array}$ & $\begin{array}{l}\text { In the biofortified relative to the } \\
\text { control group: } \\
\downarrow \text { LA:DGLA at } 2 \text { weeks } \\
\downarrow \text { LA:DGLA at } 4 \text { weeks onwards } \\
\text { (trend, not significant) }\end{array}$ & $\begin{array}{l}\text { In the biofortified relative to } \\
\text { the control group: } \\
\leftrightarrow \text { ZnT1 } \\
\leftrightarrow \text { ZnT5 } \\
\leftrightarrow \text { ZnT7 } \\
\leftrightarrow \text { ZIP1 } \\
\leftrightarrow \text { ZIP4 } \\
\leftrightarrow \text { ZIP6 } \\
\leftrightarrow \text { ZIP9 } \\
\leftrightarrow \Delta 6 \text {-desaturase }\end{array}$ & $\begin{array}{l}\text { In the biofortified relative to the control group: } \\
\downarrow \alpha \text {-diversity } \\
\text { Change in } \beta \text {-diversity } \\
\text { At the phyla level: } \\
\uparrow 1.9 \text {-fold the proportion of Actinobacteria } \\
\downarrow 1.2 \text { - and } 2.0 \text {-fold, respectively, the proportion } \\
\text { of Firmicutes and Proteobacteria } \\
\text { At the family level: } \\
\uparrow \text { abundance of Enterococcaceae } \\
\downarrow 1.7 \text {-fold the proportion of Lachnospiraceae } \\
\text { At the genera level: } \\
\uparrow \text { Enterococcus abundance } \\
\downarrow \text { Dorea abundance } \\
\uparrow 1.9 \text { - and } 1.5 \text {-fold, respectively, proportion of } \\
\text { Bifidobacterium and Lactobacillus } \\
\downarrow \text { proportion of Streptococcus (1.7-fold), } \\
\text { Coprococcus (1.4-fold), Ruminococcus (1.2-fold) } \\
\text { Faecalibacterium (2-fold), and Escherichia (2-fold) }\end{array}$ & $\begin{array}{l}\text { In the biofortified relative to } \\
\text { the control group: } \\
\leftrightarrow \text { Serum } \\
\leftrightarrow \text { Liver } \\
\leftrightarrow \text { Nail } \\
\leftrightarrow \text { Feathers }\end{array}$ \\
\hline
\end{tabular}


Table 3. Cont.

\begin{tabular}{|c|c|c|c|c|c|}
\hline \multirow[b]{2}{*}{ Reference } & \multirow{2}{*}{$\begin{array}{c}\text { Zn Content } \\
(\mu \mathrm{g} Z n / g)\end{array}$} & \multicolumn{4}{|c|}{ Zn Status Measures } \\
\hline & & $\begin{array}{c}\text { LA:DGLA } \\
\text { (Erythrocyte) }\end{array}$ & Zn-Related Gene Expression & Gut Microbiota Modulation & Other (Not Included in ZSI) \\
\hline Reed et al., 2018 [18] & $\begin{array}{l}\text { Low } \mathrm{Zn:} \\
32.8 \pm 0.17 \\
\text { (standard wheat) } \\
\text { High Zn: } \\
46.5 \pm 0.99 \\
\text { (Zn-biofortified wheat) }\end{array}$ & See Knez et al., 2018 [21] & See Knez et al., 2018 [21] & $\begin{array}{l}\text { In the high-Zn relative to the low-Zn group: } \\
\leftrightarrow \alpha \text {-diversity } \\
\text { Change in } \beta \text {-diversity } \\
\text { At the phyla level: } \\
\leftrightarrow \text { Firmicutes, Actinobacteria, and Proteobacteria } \\
\text { At the genera level: } \\
\uparrow \text { Dorea, Clostridiales, unclassified Clostridiales, } \\
\text { Ruminococcus, Lachnospiraceae, and unclassified } \\
\text { Lachnospiraceae } \\
\downarrow \text { Lactococcus, Verrucomicrobium, Bacteroides, } \\
\text { Bacteroidales, and unclassified Bacteroidales } \\
\text { At the species level: } \\
\uparrow \text { Lactobacillus reuteri } \\
\downarrow \text { Akkermansia muciniphila }\end{array}$ & See Knez et al., 2018 [21] \\
\hline Reed et al., 2015 [17] & $\begin{array}{l}\text { Zn deficient: } \\
2.5 \pm 0.02 \\
\text { Zn adequate (control): } \\
42 \pm 0.25\end{array}$ & See Reed et al., 2014 [13] & See Reed et al., 2014 [13] & $\begin{array}{l}\text { In the Zn-adequate relative to the Zn-deficient } \\
\text { group: } \\
\uparrow \alpha \text {-diversity (species richness and diversity) } \\
\text { Changes (expansion) in } \beta \text {-diversity } \\
\text { At the phyla level: } \\
\uparrow \text { Firmicutes } \\
\downarrow \text { Proteobacteria } \\
\text { At the family level: } \\
\uparrow \text { Peptostreptococcaceae and unclassified } \\
\text { Clostridiales } \\
\downarrow \text { Enterococcaceae and Enterobacteriaceae } \\
\text { At the genera level: } \\
\uparrow \text { unclassified Clostridiales and unclassified } \\
\text { Peptostreptococcaceae } \\
\downarrow \text { Enterococcus, unclassified Enterococcus, } \\
\text { unclassified Enterobacteriaceae, and unclassified } \\
\text { Ruminococcaceae } \\
\text { At the species level: } \\
\uparrow \text { Ruminococcus lactaris, Enterococcus sp., } \\
\text { Clostridium lactatifermentans, and Clostridium } \\
\text { clostridioforme } \\
\downarrow \text { Clostridium indolis and an unclassified member } \\
\text { of the Bacteroidales (Unclassified S24-7) }\end{array}$ & See Reed et al., 2014 [13] \\
\hline
\end{tabular}


Table 3. Cont.

\begin{tabular}{|c|c|c|c|c|c|}
\hline \multirow[b]{2}{*}{ Reference } & \multirow{2}{*}{$\begin{array}{l}\text { Zn Content } \\
(\mu \mathrm{g} \mathrm{Zn} / \mathrm{g})\end{array}$} & \multicolumn{4}{|c|}{ Zn Status Measures } \\
\hline & & $\begin{array}{c}\text { LA:DGLA } \\
\text { (Erythrocyte) }\end{array}$ & Zn-Related Gene Expression & Gut Microbiota Modulation & Other (Not Included in ZSI) \\
\hline Reed et al., 2014 [13] & $\begin{array}{l}\text { Zn deficient: } \\
2.5 \pm 0.02 \\
Z n \text { adequate (control): } \\
42 \pm 0.25\end{array}$ & $\begin{array}{l}\text { In the Zn-adequate relative to the } \\
\text { Zn-deficient group: } \\
\downarrow \text { LA:DGLA (1 week onwards) }\end{array}$ & $\begin{array}{l}\text { In the Zn-adequate relative to } \\
\text { the Zn-deficient group: } \\
\leftrightarrow \text { ZnT1 } \\
\leftrightarrow \text { ZnT5 } \\
\leftrightarrow \text { ZnT7 } \\
\leftrightarrow \text { ZIP6 } \\
\leftrightarrow \text { ZIP9 } \\
\uparrow \Delta 6 \text {-desaturase }\end{array}$ & See Reed et al., 2015 [17] & $\begin{array}{l}\text { In the Zn-adequate relative to } \\
\text { the Zn-deficient group: } \\
\uparrow \text { Serum Zn } \\
\uparrow \text { Feather Zn } \\
\uparrow \text { Nail Zn }\end{array}$ \\
\hline
\end{tabular}

$\leftrightarrow$ no change; $\uparrow$ increased; $\downarrow$ reduced 


\subsubsection{Additional Biomarkers of Zn Physiological Status}

Evaluation of serum, feather, and nail $\mathrm{Zn}$ content was done in three of the five studies, and evaluation of liver $\mathrm{Zn}$ content was done in one of the five studies. In Reed et al. (2014) and Knez et al. (2018), significant differences were found between serum, feather, and nail Zn content $[13,21]$. In Beasley et al. (2020), there were no significant changes in serum, feather, nail, or liver Zn content when comparing the biofortified group to the control group [20].

\subsection{Discussion}

The ZSI consists of the combination of the LA:DGLA ratio, expression of Zn-related proteins, and alterations in gut microbiome with respect to dietary $\mathrm{Zn}$ intake. In recent years, several in vivo and clinical studies have been conducted to evaluate the efficacy of the LA:DGLA ratio in assessing $\mathrm{Zn}$ physiological status with respect to dietary $\mathrm{Zn}$ intake $[13,21,33-35,38]$. Given the complexity of $\mathrm{Zn}$ metabolism, the association between mRNA gene expression of Zn-related proteins and Zn physiological status can be assessed. Additionally, as $\mathrm{Zn}$ is essential for bacteria, the abundance of $\mathrm{Zn}$-dependent microorganisms may be altered in an environment depending on $\mathrm{Zn}$ bioavailability [39].

\subsubsection{The LA:DGLA Ratio as a Potential Reactive Biomarker of Zn Physiological Status}

The previously unexplored biomarker of $\mathrm{Zn}$ physiological status related to erythrocyte $\Delta 6$-desaturation, the LA:DGLA ratio, was first evaluated in 2014 by Reed et al. [13]. The authors utilized an in vivo model (Gallus gallus) sensitive to dietary Zn manipulations $[22,40]$ and found a significant negative correlation between dietary $\mathrm{Zn}$ intake and the erythrocyte LA:DGLA ratio. In this original study, subjects were fed either a $\mathrm{Zn}$-adequate control diet $(42.3 \mu \mathrm{g} \mathrm{Zn/g})$ or a $\mathrm{Zn}$-deficient diet $(2.5 \mu \mathrm{g} \mathrm{Zn} / \mathrm{g})$ over the course of four weeks [13]. The study found that the cumulative LA:DGLA ratio was noticeably elevated in the $\mathrm{Zn}$-deficient group compared to the $\mathrm{Zn}$-adequate group, indicating the erythrocyte LA:DGLA ratio accurately differentiated $\mathrm{Zn}$ status between $\mathrm{Zn}$-adequate and $\mathrm{Zn}$-deficient subjects [13]. Further, differences in the LA:DGLA ratio were noticeable within one week, demonstrating the sensitivity of this biomarker to dietary $\mathrm{Zn}$ status and the possibility of using this biomarker for detecting early changes in Zn physiological status that may usually, due to the lack of obvious signs and symptoms, pass unrecognized [13].

This proposed biomarker of $\mathrm{Zn}$ physiological status was further evaluated in in vivo studies that studied the effects of Zn-biofortified and nicotianamine-enhanced $\mathrm{Zn}$ - and Fe-biofortified wheat on $Z n$ status [20,21]. The animal subjects in these studies consumed a wheat-based diet, which is a representative diet of target $\mathrm{Zn}$-deficient populations. In Knez et al. (2018), subjects were fed a low-Zn diet (standard wheat, $32.8 \pm 0.17 \mu \mathrm{g} \mathrm{Zn/g)} \mathrm{or}$ high-Zn diet (Zn-biofortified wheat, $46.5 \pm 0.99 \mu \mathrm{g} \mathrm{Zn/g)} \mathrm{over} \mathrm{the} \mathrm{course} \mathrm{of} \mathrm{six} \mathrm{weeks} \mathrm{[21].}$ The LA:DGLA ratio was higher in the low-Zn group at all time points measured (weeks 2, 4 , and 6), and the difference in Zn dosing in Knez et al. (2018) was only $14 \mu \mathrm{g} \mathrm{Zn/g}$ versus $40 \mu \mathrm{g} \mathrm{Zn/g}$ in Reed et al. (2014) [13,21]. This demonstrated that with only a $14 \mu \mathrm{g} \mathrm{Zn/g}$ differential in dietary $\mathrm{Zn}$ content, the LA:DGLA ratio differentiated clearly between treatment groups, thus demonstrating the sensitivity of the biomarker to change in accordance with dietary Zn intake [21]. In Beasley et al. (2020) [20], subjects were given a biofortified diet (nicotianamine-enhanced Zn- and Fe-biofortified wheat) or control (standard wheat) diet, wherein the biofortified subjects had lower $\mathrm{Zn}$ consumption than the control subjects over the course of the six-week study (21.0 mg compared to $22.1 \mathrm{mg} \mathrm{Zn}$, respectively). It was found that the LA:DGLA ratio was significantly decreased at week 2 and there was a trend of decreased LA:DGLA from week 4 onwards in the biofortified group relative to the control

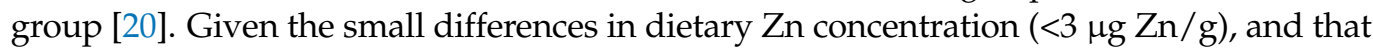
the biofortified group had lower $\mathrm{Zn}$ consumption than the control group, the authors posited that the biofortified chickens may have had improved Zn bioavailability due to consumption of increased dietary nicotianamine, although whether nicotianamine or its metabolite (2'deoxymugineic acid) increase $\mathrm{Zn}$ bioavailability requires further investigation [20]. 
Traditional biomarkers of $\mathrm{Zn}$ status, such as $\mathrm{Zn}$ in serum and tissues (feather and nail) were also assessed in the aforementioned in vivo studies. Given the wide differences in $\mathrm{Zn}$ dietary content in Reed et al. (2014) and Knez et al. (2018), the concentration of Zn in serum, feather, and nail was greater in the treatment groups with higher $\mathrm{Zn}$ dietary intake than in the treatment groups with lower $\mathrm{Zn}$ intake $(p<0.05)[13,21]$. In Beasley et al. (2020), Zn concentration in serum, nail, and feather samples were unchanged in the biofortified subjects relative to the control subjects, suggesting that Zn status was unchanged [20]. However, given the small differences in dietary $\mathrm{Zn}$ consumption $(21.0 \mathrm{mg}$ for biofortified subjects compared to $22.1 \mathrm{mg}$ Zn for control subjects), the traditional biomarkers of Zn status may not have been sensitive enough when compared to the LA:DGLA ratio, where a significant difference in LA:DGLA ratio was found between treatment groups at the two-week timepoint, suggesting differences in Zn status [20]. These observations are in agreement with previous research that suggested the problematic sensitivity of plasma $\mathrm{Zn}$ as a biomarker of $\mathrm{Zn}$ status, and further highlights the need to develop sensitive biomarkers of Zn status [12,41].

This proposed biomarker of Zn physiological status has been further evaluated in clinical studies and found to change in accordance with dietary Zn intake [33-35]. Knez et al. (2017) found that in healthy human adult volunteers, changes in plasma LA:DGLA ratio corresponded to dietary $\mathrm{Zn}$ intake [35]. Further, the study found that although plasma Zn concentrations remained unchanged, the LA:DGLA ratio was increased in participants with lower dietary Zn intakes [35]. In 2019, Knez et al. found that subjects with dyslipidemia had inadequate dietary intakes of Zn and a low plasma Zn status. The study also found no correlations between plasma $\mathrm{Zn}$ and dietary $\mathrm{Zn}$ intake, but found an inverse correlation between dietary $\mathrm{Zn}$ intake and the LA:DGLA ratio, reconfirming the sensitivity of the LA:DGLA ratio in humans [38]. The LA:DGLA ratio was assessed in a randomized controlled trial in Beninese children, where a negative association was found between the LA:DGLA ratio and plasma $\mathrm{Zn}$ concentration at the study baseline, further supporting the value of the LA:DGLA ratio as a potential biomarker of Zn physiological status [34]. Monteiro et al. (2021) evaluated the association between $\mathrm{Zn}$ and polyunsaturated fatty acid (PUFA) intake related to the LA:DGLA ratio, and found an inverse correlation between the LA:DGLA ratio and serum $\mathrm{Zn}$, and associated the LA:DGLA ratio with dietary patterns related to Zn and PUFA intake [33]. Further, King (2018) discussed how in humans, enzymes such as $\Delta 6$-desaturase (FADS2, or fatty acid desaturase 2) involved in metabolizing linoleic acid are sensitive to modest changes in dietary $\mathrm{Zn}$ [41]. Given that the LA-to-DGLA conversion pathway takes place in the red blood membrane, and red blood cell fatty acid composition is more stable over time within a person and is unaffected by fasting status, future clinical studies should focus on determining the LA:DGLA ratio in the red blood cell fraction instead of the plasma or serum fraction $[42,43]$.

\subsubsection{Zn-Related Gene Expression in Relation to Zn Dietary Intake In Vivo}

Previous in vivo studies have documented that even mild Zn deficiency can alter Zn transporter gene expression and brush border membrane enzyme activity [14,15]. As Zn exists as a charged, hydrophobic ion, specialized protein transporters are required to move $\mathrm{Zn}$ across the plasma membranes for cellular uptake and release. Two Zn transporter families work together to regulate $\mathrm{Zn}$ homeostasis in the cell, where $\mathrm{ZnT}$ proteins ( $\mathrm{Zn}$ efflux transporters, SLC30 family) export Zn from the cytoplasm, whereas ZIP proteins (Zn influx transporters, SLC39 family) import Zn into the cytoplasm [44-47]. ZnT1 is the major Zn export protein, and ZIP4 is the most important Zn import protein, where ZnT1 and ZIP4 expression changes have been associated with the molecular basis of systemic Zn homeostatic regulation [6,48,49]. However, both increased and decreased ZnT and ZIP expression have been demonstrated in response to $\mathrm{Zn}$ deficiency $[6,45,47]$.

Gene expression of duodenal Zn-related transporters was assessed in relation to Zn dietary intake. In Reed et al. (2014), there were no significant changes in gene expression of $\mathrm{Zn}$ transport proteins between the Zn-adequate and Zn-deficient groups, suggesting that these mRNA gene expression biomarkers may not be sensitive enough to reveal differences 
in $\mathrm{Zn}$ status in a four-week feeding trial, and lack of gene expression changes may have been a compensatory mechanism by the subjects to a Zn-deficient diet [13]. In Knez et al. (2018), which was a six-week feeding trial, the gene expression of tested $\mathrm{Zn}$ transporters (ZnT1, ZnT5, ZnT7, ZIP4, ZIP6, ZIP9) were significantly downregulated in the high-Zn group (Zn-biofortified wheat) compared to the low-Zn (control) group [21]. Given that the Knez et al. (2018) study was over a longer period of time, and the differential in $\mathrm{Zn}$ concentration between the experimental and control group was not as wide as that in Reed et al. (2014) $(46.5 \mu \mathrm{g} / \mathrm{g}$ versus $32.8 \mu \mathrm{g} / \mathrm{g}$ in high-Zn versus low-Zn in Knez et al. (2018), compared to $42 \mu \mathrm{g} / \mathrm{g}$ versus $2.5 \mu \mathrm{g} / \mathrm{g}$ in Zn-adequate versus $\mathrm{Zn}$-deficient), it is possible that the significant changes in $\mathrm{Zn}$ transporter gene expression were associated with the longer duration of the feeding trial $[13,21]$.

Hepatic $\Delta 6$-desaturase mRNA gene expression was also assessed. $\mathrm{Zn}$ is an essential cofactor for the $\Delta 6$-desaturase enzyme; thus, $\mathrm{Zn}$ deficiency affects the function and gene expression of $\Delta 6$-desaturase [13,32,50,51]. In Reed et al. (2014) and Knez et al. (2018), $\Delta 6$ desaturase gene expression was significantly altered in the experimental group with higher Zn consumption [13,21]. In Beasley et al. (2020), there were no changes in $\Delta 6$-desaturase gene expression, potentially due to the small differences in dietary $\mathrm{Zn}$ consumption between the experimental and control groups [20]. Taken together, these findings suggest differential dietary Zn can alter Zn-related gene expression.

\subsubsection{Gut Microbiome as a Potential Indicator of Zn Status}

Bacteria that colonize the gastrointestinal tract are dependent on minerals such as $\mathrm{Zn}$, where bacterial metabolites can contribute to mineral solubility [19,39]. Additionally, as $\mathrm{Zn}$ is essential for bacteria, the abundance of $\mathrm{Zn}$-dependent microorganisms may be dependent on Zn bioavailability [39]. The three studies presented performed 16S rRNA gene sequencing to elucidate the effects of $\mathrm{Zn}$ consumption in relation to bacterial phylogeny and taxonomy $[17,18,20]$. One study, which had the largest differential in $\mathrm{Zn}$ content between experimental groups, found a significant decrease in $\alpha$-diversity with a $Z n$-deficient diet compared to a Zn-adequate diet (Chao1 for species richness and total observed OTUs for diversity), suggesting that a Zn-depleted environment may lead to a less diverse microbial community, preferentially composed of species that are viable under low $\mathrm{Zn}$ conditions [17]. Changes in $\beta$-diversity were found in all three studies between the treatment and the control groups, though the change is not necessarily indicative of either beneficial or negative variations in bacterial taxa $[17,18,20]$.

Reed et al. (2015) found an increase in prevalence of Ruminococcus lactaris, Enterococcus sp., Clostridium lactatifermentans, and Clostridium clostridioforme, and a decrease in prevalence of Clostridium indolis and an unclassified member of the Bacteroidales (Unclassified S24-7) in the group that received the $\mathrm{Zn}$-adequate diet compared to the group that received a Zn-deficient diet. With chronic $\mathrm{Zn}$ deficiency, a decrease in the prevalence of members of the Firmicutes phylum, such as the genera Clostridium, which contains SCFA producers, was also found [17]. Increased SCFA production lowers intestinal luminal $\mathrm{pH}$, which has been associated with preventing proliferation of potentially pathogenic bacteria and increasing Zn bioavailability and uptake [52,53]. Reed et al. (2018) observed an expansion in L. reuteri, and members of Dorea, Clostridiales, unclassified Clostridiales, Ruminococcus, Lachnospiraceae, and unclassified Lachnospiraceae genera in the group that received the high-Zn diet compared to the group receiving the low-Zn diet [18]. The Ruminococcus and Clostridiales genera include species of bacteria that are known SCFA producers $[54,55]$. Additionally, bacteria from the Lachnospiraceae family, such as the Blautia genera, are among the main producers of SCFAs [56]. Decreased abundance of Lachnospiraceae has been associated with negative health implications resulting from the loss of numerous beneficial functions, such as SCFA production, performed by members of this family $[57,58]$. LEfSe was utilized in Reed et al. (2018) to investigate significant bacterial biomarkers that could identify differences in the gut microbiota of treatment groups, where a four-fold increase in the Lactobacillaceae phyla was found [18]. Members of the Lactobacillaceae phyla have 
been shown to improve gut health by producing SCFAs; decreasing the colonization of pathogenic microorganisms, such as Salmonella spp. and enteropathogenic E. coli; and increasing villus surface area and goblet cell number per villi [59-61]. In Beasley et al. (2020), the authors observed an increase in the abundance of the Actinobacteria phylum and a reduction in the abundance of Firmicutes and Proteobacteria in the biofortified group compared to the control group [20]. An increase in abundance of Actinobacteria phyla has been associated with the consumption of plant dietary fiber, suggesting a potential beneficial effect of this phylum on intestinal health [19]. All studies suggested alterations in gut microbiota composition in association with the abundance and capacity of resident intestinal microbiota to provide SCFAs in the lower Zn intake or lower Zn bioavailability group, which can further deplete Zn bioavailability in an already Zn-insufficient state.

Through metagenomic analysis, the presented three studies found alterations in predicted Kyoto Encyclopedia of Genes and Genomes (KEGG) pathways. Reed et al. (2014) found decreased expression of pathways related to mineral (i.e., Zn) absorption and carbohydrate digestion and fermentation, where the latter pathway may also contribute to the depression in SCFA production, which has been associated with improving $\mathrm{Zn}$ bioavailability [17]. KEGG pathway analysis in Reed et al. (2018) found six bacterial biosynthetic pathways to be depleted in the low-Zn diet group, where pathways responsible for bile acid production, cytochrome p450 activity, and glycan metabolism were found to be significantly depleted and posited to reflect the decreased concentration of bioavailable $\mathrm{Zn}$ in the intestinal lumen [18]. Beasley et al. (2020) found the metagenomic potential of microbial glycolysis/gluconeogenesis significantly increased and microbial tropane piperidine and pyridine alkaloid biosynthesis significantly decreased in the biofortified group's microbial populations relative to the control [20]. Altogether, the microbial effects presented in these studies suggest that a significant remodeling of the intestinal microbiota occurs in animal subjects receiving diets with differential content and bioavailability of $\mathrm{Zn}$.

\section{Development of the ZSI}

\subsection{Statistical Strategy for Creating the Zinc Status Index (ZSI)}

Using data from dietary-controlled experiments in three studies conducted in Gallus gallus, data were obtained for three types of predictors: the LA:DGLA ratio, gene expression of selected genes associated with $\mathrm{Zn}$ metabolism, and microbiome factors. The training sample utilized data from Knez et al. (2017), Reed et al. (2018), and Beasley et al. (2020). The studies selected investigated differential dietary $\mathrm{Zn}$ in the context of a complete diet. A training sample of $n=59$ and a total of 25 potential predictors for the $Z n$ status, including LA:DGLA, eight Zn-dependent genes, and 16 bacteria genera, was utilized for ZSI prototype development (Table 4). Note that not all 59 samples have data for all 25 predictors.

We used these 25 variables as predictors for diet status (control vs. Zn biofortified) and fitted a binary classifier. Specifically, we used the logistic regression and the CART (classification and regression tree) methods. We eliminated from the fitted model any variables that had no predictive power (namely, they were not associated with the binary diet variable, meaning changes in dietary $\mathrm{Zn}$ intake). The remaining predictors were used to define our ZSI, which allowed us to predict the probability of Zn-adequacy or -deficiency status. Additionally, when obtaining the prediction formulas for this study and fitting the logistic model, we added the experiment as a factor to control for differences between experiments. Supposing that we have a total of four predictors $\left(\mathrm{x}_{1}, \ldots, \mathrm{x}_{4}\right)$ that were found to be significantly associated with the diet variable, then the logistic formula is

$$
\log \frac{p}{1-p}=\beta_{0}+\beta_{1} x_{1}+\beta_{2} x_{2}+\beta_{3} x_{3}+\beta_{4} x_{4}
$$

where $p$ is the probability that a subject has an adequate level of $Z n$, and $\beta_{i}$ is the coefficient obtained from our training data. Then, the index was simply obtained by measuring only $\mathrm{x}_{1}, \ldots, \mathrm{x}_{4}$ for new samples, entering them into the formula, and determining $\mathrm{Zn}$ physiological status based on whether $\log (p / 1-p)$ was greater than a certain threshold. 
For example, we could set the $\mathrm{Zn}$ status as deficient if $\log _{2}(p / 1-p)<-2$, that is, the odds that the $\mathrm{Zn}$ level is adequate, was less than $1 / 4$ and the probability that the level of $\mathrm{Zn}$ was adequate was 0.25 . Stricter thresholds could be used.

Table 4. Potential predictors of Zn status used in ZSI development We currently have a training sample of $n=59$ Gallus gallus and a total of 25 potential predictors for Zn status, including LA:DGLA, eight genes, and 16 bacteria genera.

\begin{tabular}{|c|c|c|c|}
\hline LA:DGLA & Zn-Related Gene Expression & & Gut Bacteria Genera \\
\hline $\begin{array}{l}\text { LA:DGLA ratio in } \\
\text { erythrocyte }\end{array}$ & $\begin{array}{ll}\text { 1. } & \text { ZnT1 } \\
\text { 2. } & \text { ZnT5 } \\
\text { 3. } & \text { ZnT7 } \\
\text { 4. } & \text { ZIP1 } \\
\text { 5. } & \text { ZIP4 } \\
\text { 6. } & \text { ZIP6 } \\
\text { 7. } & \text { ZIP9 } \\
\text { 8. } & \Delta 6 \text {-desaturase }\end{array}$ & $\begin{array}{l}1 . \\
2 . \\
3 . \\
4 . \\
5 . \\
6 . \\
7 . \\
8 . \\
9 . \\
10 . \\
11 . \\
12 . \\
13 . \\
14 . \\
15 . \\
16 .\end{array}$ & $\begin{array}{l}\text { Anaerotruncus } \\
\text { Bifidobacterium } \\
\text { Blautia } \\
\text { Coprococcus } \\
\text { Escherichia } \\
\text { Faecalibacterium } \\
\text { Lactobacillus } \\
\text { Oscillospira } \\
\text { Ruminococcus } \\
\text { Streptococcus } \\
\text { Sutterella } \\
\text { unclassified Clostridiales } \\
\text { unclassified Enterobacteriaceae } \\
\text { unclassified Lachnospiraceae } \\
\text { unclassified Ruminococcaceae } \\
\text { Family: Lachnospiraceae }\end{array}$ \\
\hline
\end{tabular}

Our index is probabilistic in nature, so given the data for the selected predictors (or some of them), we could determine the probability of whether the $\mathrm{Zn}$ levels were adequate or deficient.

\subsection{Examples of the ZSI as a Predictor of Zn Status}

We obtained the following estimations (examples) for the probability that a hypothetical human or animal subject is $\mathrm{Zn}$ adequate. In the following examples, $p$ ranged from 0 to 1 , and we set preliminary quintiles for estimated Zn status as shown in Table 5.

Table 5. Estimated Zn status based on preliminary ranges of predicted probability $(p)$ of Zn adequacy.

\begin{tabular}{cc}
\hline Predicted Probability of Zn Adequacy $(p)$ & Estimated Zn Status \\
\hline $0 \leq p \leq 0.2$ & Severely Zn deficient \\
$0.2<p \leq 0.4$ & Moderately Zn deficient \\
$0.4<p \leq 0.6$ & Mildly Zn deficient \\
$0.6<p \leq 0.8$ & Minimally Zn adequate \\
$0.8<p \leq 1$ & Zn adequate \\
\hline
\end{tabular}

Example 1. (Relevant for humans and animal models): Using data from our previous experiments, we obtained the following estimation for the probability that a subject is $\mathrm{Zn}$ deficient:

$$
\log \frac{p}{1-p}=5.18-0.015 x_{1}-0.26 x_{2}+43.39 x_{3}
$$

where $x_{1}$ is the LA:DGLA level, $x_{2}$ is the $\Delta 6$-desaturase expression, $x_{3}$ is the Blautia relative abundance, and $p$ is the probability that a subject has an adequate level of $\mathrm{Zn}$.

For example 1, as depicted in Table 6, hypothetical subject A, whose LA:DGLA ratio is at the 50th percentile $\left(x_{1}=50\right)$ and whose $\Delta 6$-desaturase expression levels and Blautia relative abundance are equal to the median $\left(x_{2}=192, x_{3}=0.021\right)$, the predicted probability that subject $\mathrm{A}$ has an adequate $\mathrm{Zn}$ level is 0.59 , with an estimated $\mathrm{Zn}$ status of mildly $\mathrm{Zn}$ deficient. If subject $\mathrm{B}$ has an LA:DGLA level equal to the 20th percentile $\left(\mathrm{x}_{1}=38\right)$ and the $\Delta 6$-desaturase and Blautia relative abundance are equal to the median, then the 
probability that subject $B$ is $\mathrm{Zn}$ adequate is 0.64 , corresponding to an estimated minimally $Z n$-adequate status. For subject $C$, the LA:DGLA level and Blautia relative abundance are the same as subject $A$, but subject $C$ has a $\Delta 6$-desaturase expression in the 80 th percentile $\left(x_{2}=249\right)$, so the predicted probability that subject $C$ is $Z n$ adequate is 0.25 , with an estimated moderately Zn-deficient status. Finally, if the LA:DGLA level and $\Delta 6$-desaturase expression remain the same as subject A, but subject D's Blautia relative abundance is at the 80 th percentile $\left(x_{3}=0.035\right)$, the probability that subject $D$ is $Z n$ adequate increases to 0.73 , with an estimated minimally $\mathrm{Zn}$-adequate status.

Table 6. Predicted probability of Zn adequacy of hypothetical subjects using the above ZSI example $1^{1}$.

\begin{tabular}{|c|c|c|c|c|c|c|c|c|}
\hline \multirow{2}{*}{$\begin{array}{l}\text { Hypothetical } \\
\text { Subject }\end{array}$} & \multicolumn{2}{|c|}{ LA:DGLA ( $\left.\mathrm{x}_{1}\right)$} & \multicolumn{2}{|c|}{$\Delta 6$-Desaturase $\left(\mathrm{x}_{2}\right)$} & \multicolumn{2}{|c|}{ Blautia $\left(\mathrm{x}_{3}\right)$} & \multirow{2}{*}{$\begin{array}{l}\text { Predicted Probability } \\
\text { of Zn Adequacy }(p)\end{array}$} & \multirow{2}{*}{$\begin{array}{l}\text { Estimated } \\
\text { Zn Status }\end{array}$} \\
\hline & Percentile & Value (AU) & Percentile & Value (AU) & Percentile & Value (AU) & & \\
\hline Subject $1 \mathrm{~A}$ & 50 & 50 & 50 & 192 & 50 & 0.021 & 0.59 & $\begin{array}{l}\text { Mildly Zn } \\
\text { deficient }\end{array}$ \\
\hline Subject 1B & 20 & 38 & 50 & 192 & 50 & 0.021 & 0.64 & $\begin{array}{l}\text { Minimally } \\
\text { Zn adequate }\end{array}$ \\
\hline Subject 1C & 50 & 50 & 80 & 249 & 50 & 0.021 & 0.25 & $\begin{array}{l}\text { Moderately } \\
\text { Zn deficient }\end{array}$ \\
\hline Subject 1D & 50 & 50 & 50 & 192 & 80 & 0.035 & 0.73 & $\begin{array}{l}\text { Minimally } \\
\text { Zn adequate }\end{array}$ \\
\hline
\end{tabular}

${ }^{1}$ Note that in all these hypothetical scenarios we assume that the data have been standardized relative to a reference experiment.

Example 2. (Relevant for humans and animal models): Using data from our previous experiments, we obtained the following estimation for the probability that a subject is $\mathrm{Zn}$ deficient:

$$
\log \frac{p}{1-p}=3.95-0.016 \mathrm{x}_{1}-0.31 \mathrm{x}_{2}+145.7 \mathrm{x}_{3}
$$

where $x_{1}$ is the LA:DGLA level, $x_{2}$ is the $\Delta 6$-desaturase expression, $x_{3}$ is the unclassified Lachnospiraceae relative abundance, and $p$ is the probability that a subject has adequate level of $\mathrm{Zn}$.

For example 2, as depicted in Table 7, hypothetical subject A, whose LA:DGLA is at the 50th percentile $\left(x_{1}=50\right)$ and whose $\Delta 6$-desaturase expression levels and unclassified Lachnospiraceae relative abundance are equal to the median and 20th percentile $\left(\mathrm{x}_{2}=192\right.$ and $\mathrm{x}_{3}=0.013$, respectively), the predicted probability that subject $\mathrm{A}$ has an adequate $\mathrm{Zn}$ level is 0.33 , with an estimated $\mathrm{Zn}$ status of moderately $\mathrm{Zn}$ deficient. If subject $\mathrm{B}$ has a LA:DGLA level equal to the 20th percentile $\left(\mathrm{x}_{1}=38\right)$ and the $\Delta 6$-desaturase and unclassified Lachnospiraceae relative abundance are equal to that of subject $A$, then the probability that subject $B$ is $\mathrm{Zn}$ adequate is 0.37 , corresponding to an estimated moderately $\mathrm{Zn}$-adequate status. For subject C, the LA:DGLA level and unclassified Lachnospiraceae relative abundance are the same as subject $A$, but subject $C$ has a $\Delta 6$-desaturase expression that is in the 20th percentile $\left(x_{2}=153\right)$, where the predicted probability that subject $C$ is $Z n$ adequate is 0.62 , with an estimated minimally Zn-deficient status. Finally, if the LA:DGLA level and $\Delta 6$-desaturase expression remain the same as subject $\mathrm{A}$, but subject $\mathrm{D}^{\prime}$ s unclassified Lachnospiraceae relative abundance is at the 80th percentile $\left(x_{3}=0.034\right)$, the probability that subject $\mathrm{D}$ is $\mathrm{Zn}$ adequate increases to 0.90 , with an estimated $\mathrm{Zn}$-adequate status.

Example 3. (Relevant for animal models): Using data from our previous experiments, we obtained the following estimation for the probability that an animal subject is $\mathrm{Zn}$-deficient:

$$
\log \frac{p}{1-p}=15.9-0.05 \mathrm{x}_{1}-0.03 \mathrm{x}_{2}-0.26 \mathrm{x}_{3}
$$

where $x_{1}$ is the LA:DGLA level, $x_{2}$ is the $\Delta 6$-desaturase expression, $x_{3}$ is the ZIP9 expression, and $p$ is the probability that a subject has adequate level of $\mathrm{Zn}$. 
For example 3, as depicted in Table 8, where LA:DGLA is at the 80th percentile $\left(x_{1}=70\right)$ and the $\Delta 6$-desaturase and ZIP9 expression levels are equal to the median $\left(x_{2}=197\right.$, $\mathrm{x}_{3}=31$ ), the predicted probability that subject $\mathrm{A}$ has an adequate $\mathrm{Zn}$ level is 0.28 , with an estimated moderately Zn-deficient status. If animal subject B has a LA:DGLA level at the 20th percentile $\left(x_{1}=38\right)$ and the $\Delta 6$-desaturase and ZIP9 expression remain the same compared to animal subject $\mathrm{A}$, then the probability that subject $\mathrm{B}$ is $\mathrm{Zn}$ adequate is 0.67 , corresponding to an estimated minimally Zn-adequate status. For animal subject C, the LA:DGLA level and ZIP9 are the same as animal subject A, but animal subject C has a $\Delta 6$-desaturase expression that is in the 20th percentile $\left(x_{2}=153\right)$, so the predicted probability that subject $C$ is $\mathrm{Zn}$ adequate is 0.6 , with an estimated mildly $\mathrm{Zn}$-deficient status. Finally, if the LA:DGLA level and $\Delta 6$-desaturase expression remain the same as animal subject A, but subject D's ZIP9 expression level is at the 90th percentile $\left(x_{3}=45\right)$, the probability that animal subject $\mathrm{D}$ is $\mathrm{Zn}$ adequate drops to 0.016 , with an estimated severely Zn-deficient status.

Table 7. Predicted probability of Zn adequacy of hypothetical subjects using the above ZSI example $2^{1}$.

\begin{tabular}{|c|c|c|c|c|c|c|c|c|}
\hline \multirow{2}{*}{$\begin{array}{l}\text { Hypothetical } \\
\text { Subject }\end{array}$} & \multicolumn{2}{|c|}{ LA:DGLA $\left(\mathrm{x}_{1}\right)$} & \multicolumn{2}{|c|}{$\Delta 6$-Desaturase $\left(\mathrm{x}_{2}\right)$} & \multicolumn{2}{|c|}{$\begin{array}{c}\text { Unclassified } \\
\text { Lachnospiraceae }\left(\mathrm{x}_{3}\right)\end{array}$} & \multirow{2}{*}{$\begin{array}{l}\text { Predicted Probability } \\
\text { of Zn Adequacy }(p)\end{array}$} & \multirow{2}{*}{$\begin{array}{l}\text { Estimated } \\
\text { Zn Status }\end{array}$} \\
\hline & Percentile & Value (AU) & Percentile & Value (AU) & Percentile & Value (AU) & & \\
\hline Subject 2A & 50 & 50 & 50 & 192 & 20 & 0.013 & 0.33 & $\begin{array}{l}\text { Moderately } \\
\text { Zn deficient }\end{array}$ \\
\hline Subject 2B & 20 & 38 & 50 & 192 & 20 & 0.013 & 0.37 & $\begin{array}{l}\text { Moderately } \\
\text { Zn deficient }\end{array}$ \\
\hline Subject 2C & 50 & 50 & 20 & 153 & 20 & 0.013 & 0.62 & $\begin{array}{c}\text { Minimally } \\
\text { Zn adequate }\end{array}$ \\
\hline Subject 2D & 50 & 50 & 50 & 192 & 80 & 0.034 & 0.90 & Zn adequate \\
\hline
\end{tabular}

${ }^{1}$ Note that in all these hypothetical scenarios we assume that the data have been standardized relative to a reference experiment.

Table 8. Predicted probability of Zn adequacy of hypothetical animal subjects using the above ZSI example $3^{1}$.

\begin{tabular}{|c|c|c|c|c|c|c|c|c|}
\hline \multirow{2}{*}{$\begin{array}{l}\text { Hypothetical } \\
\text { Subject }\end{array}$} & \multicolumn{2}{|c|}{ LA:DGLA $\left(x_{1}\right)$} & \multicolumn{2}{|c|}{$\Delta 6$-Desaturase $\left(x_{2}\right)$} & \multicolumn{2}{|c|}{$\operatorname{ZIP9}\left(x_{3}\right)$} & \multirow{2}{*}{$\begin{array}{l}\text { Predicted Probability } \\
\text { of Zn Adequacy }(p)\end{array}$} & \multirow{2}{*}{$\begin{array}{l}\text { Estimated } \\
\text { Zn Status }\end{array}$} \\
\hline & Percentile & Value (AU) & Percentile & Value (AU) & Percentile & Value (AU) & & \\
\hline Subject 3A & 80 & 70 & 50 & 197 & 50 & 31 & 0.28 & $\begin{array}{l}\text { Moderately } \\
\text { Zn deficient }\end{array}$ \\
\hline Subject 3B & 20 & 38 & 50 & 197 & 50 & 31 & 0.67 & $\begin{array}{l}\text { Minimally } \\
\text { Zn adequate }\end{array}$ \\
\hline Subject 3C & 80 & 70 & 20 & 153 & 50 & 31 & 0.60 & $\begin{array}{l}\text { Mildly Zn } \\
\text { deficient }\end{array}$ \\
\hline Subject 3D & 80 & 70 & 50 & 197 & 90 & 45 & 0.016 & $\begin{array}{l}\text { Severely Zn } \\
\text { deficient }\end{array}$ \\
\hline
\end{tabular}

${ }^{1}$ Note that in all these hypothetical scenarios we assume that the data have been standardized relative to a reference experiment.

\subsection{Zinc Status Index as an Accurate Predictor of Zn Physiological Status}

$\mathrm{Zn}$ is an essential mineral with catalytic, structural, and regulatory functions with sophisticated homeostatic control, making it difficult to identify Zn inadequacy [12,62]. It remains a scientific challenge to obtain an accurate picture of $\mathrm{Zn}$ status of both various population groups and individuals [63]. Considering the complexity of Zn metabolism, the establishment of a panel of biochemical indices is necessary to reliably assess $\mathrm{Zn}$ status, especially in cases of mild to moderate Zn deficiency. As such, we developed the ZSI prediction model, which consists of a three-pillar formula: (1) the LA:DGLA ratio, (2) mRNA gene expression of Zn-related proteins, and (3) fecal microbial ecology profiling. The formula provides a clear and accurate measurement of Zn physiological status. Each of the three pillars has been shown to be altered with changes in dietary $\mathrm{Zn}$ intake and Zn bioavailability $[13,17,18,20,21,35]$. To illustrate the potential contribution of biomarkers other than the LA:DGLA ratio, consider hypothetical subject 2D, for example. In Table 7 , we see that the predicted probability of $\mathrm{Zn}$ adequacy for this subject is 0.9 (estimated $\mathrm{Zn}$ adequate status). Removing the Lachnospiraceae predictor from Equation (3) yields a 
predicted value of 0.06 (corresponding to an estimated severely $\mathrm{Zn}$-deficient status). It is clear that a model with gene expression and microbiome biomarkers in addition to the LA:DGLA ratio can have a substantial impact on the accuracy of the ZSI. Our ZSI will improve the understanding of $\mathrm{Zn}$ nutrition, physiological status, and severity of potential deficiency (Figure 1).

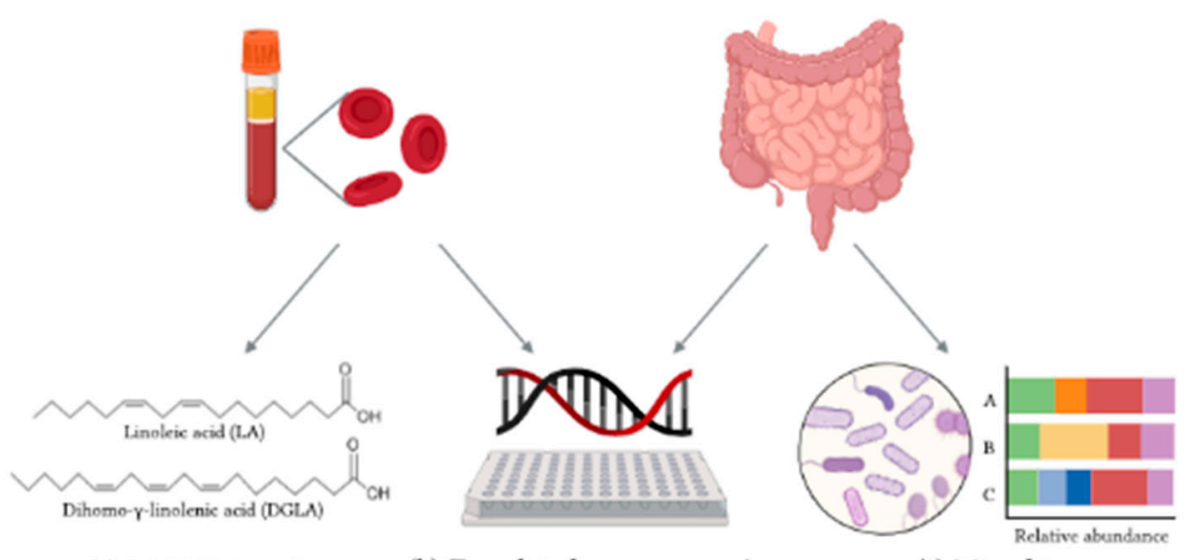

(a) LA:DGLA ratio

(b) Zn-related gene expression

(c) Microbiome

\section{Zinc Status Index (ZSI)}

$\log \frac{p}{1-p}=\beta_{0}+\beta_{1} x_{1}+\beta_{2} x_{2}+\beta_{3} x_{3}+\beta_{4} x_{4}$

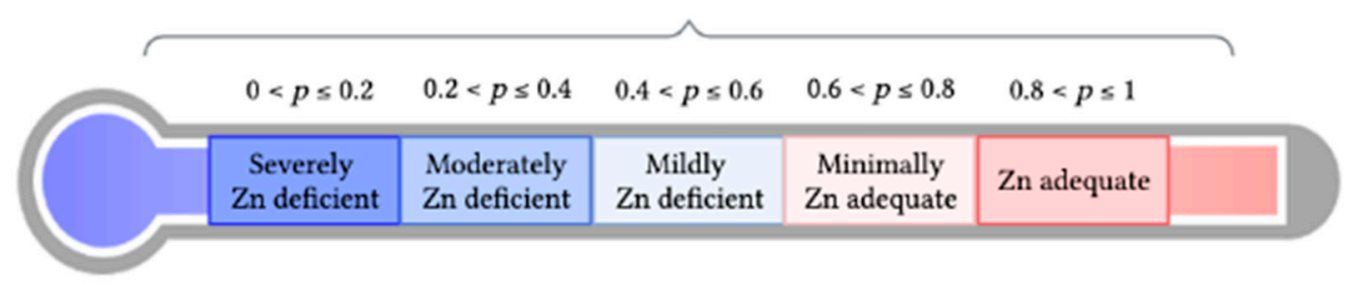

Figure 1. Schematic of ZSI prediction model development. Three pillars, (a) LA:DGLA ratio, (b) Zn-related gene expression, and (c) gut microbiome profile, were utilized for development of the ZSI. Based on our initial ZSI prediction model, we may set preliminary quintiles for $\mathrm{Zn}$ status levels based on the predicted probability of $\mathrm{Zn}$ adequacy.

Three examples utilizing our prototype ZSI to estimate Zn status were provided. Examples 1 and 2 can be utilized for both clinical trials (human studies) and animal studies, as LA:DGLA level and $\triangle 6$-desaturase (FADS2) gene expression can be obtained from blood samples (erythrocyte fraction) and gut microbiome profiling can be obtained from fecal samples. Example 3 is most relevant for animal models due to the invasive nature of sample collection (duodenal sample) for ZIP9 gene expression. When comparing subjects $A$ and $B$ from our three examples, where only the LA:DGLA level $\left(x_{1}\right)$ is changed versus the other predictors $\left(x_{2}\right.$ and $\left.x_{3}\right)$, the decrease in LA:DGLA level was associated with an improvement in $\mathrm{Zn}$ status, in line with previous experiments due to the $\mathrm{Zn}$ requirement of $\Delta 6$-desaturase in the LA-to-DGLA conversion pathway [13,21,64]. When comparing subject $A$ to subject $C$ in all three examples, where the $\Delta 6$-desaturase expression level $\left(\mathrm{x}_{2}\right)$ is altered and the other predictors remain the same ( $\mathrm{x}_{1}$ and $\mathrm{x}_{3}$, respectively), lower $\Delta 6$-desaturase expression was found to be associated with improved $\mathrm{Zn}$ status, supported by previous studies where $\Delta 6$-desaturase gene expression was significantly altered with differential dietary $\mathrm{Zn}$ consumption [21]. In example 3, when comparing subject $\mathrm{A}$ to subject $\mathrm{D}$, where ZIP9 expression $\left(\mathrm{x}_{3}\right)$ is higher in subject $\mathrm{D}$ and LA:DGLA level and $\Delta 6$-desaturase ( $x_{1}$ and $x_{2}$, respectively) remain the same, the estimated $\mathrm{Zn}$ status was severely $\mathrm{Zn}$ deficient $(p=0.016)$ in subject $\mathrm{D}$ versus moderately $\mathrm{Zn}$ deficient $(p=0.28)$ 
for subject $\mathrm{A}$. This aligns with previous studies where $\mathrm{Zn}$ transporter gene expression was significantly altered with differential $\mathrm{Zn}$ status [21]. In example 1, if the LA:DGLA level $\left(\mathrm{x}_{1}\right)$ and $\Delta 6$-desaturase expression $\left(\mathrm{x}_{2}\right)$ remain the same as subject $\mathrm{A}$, but subject $\mathrm{D}^{\prime} \mathrm{s}$ Blautia relative abundance is at the 80th percentile $\left(x_{3}=0.035\right)$ versus the 50th percentile $\left(x_{3}=0.021\right)$ for subject $A$, subject D's estimated $Z n$ status was minimally $Z n$ adequate $(p=0.73)$ versus subject A's estimated Zn status of mildly Zn deficient $(p=0.59)$. The Blautia genera includes SCFA producers, where SCFA activity has been associated with reducing levels of inflammatory markers and interacting with the host immune system [56]. Further, when comparing subjects A and D in example 3, where only the unclassified Lachnospiraceae abundance $\left(x_{3}\right)$ is changed and LA:DGLA level and $\Delta 6$-desaturase gene expression ( $x_{1}$ and $\mathrm{x}_{2}$, respectively) remain the same, the increase in unclassified Lachnospiraceae abundance from the 20th percentile in subject $A$ to the 80 th percentile in subject $D$ was associated with an improvement in predicted $\mathrm{Zn}$ status from moderately $\mathrm{Zn}$ deficient to $\mathrm{Zn}$ adequate. Both Blautia and unclassified Lachnospiraceae belong to the Lachnospriaceae family, and Lachnospiraceae play a key role in carbohydrate metabolism [58,65]. Metagenomic analysis found that a Zn-deficient state was associated with decreased expression of pathways related to carbohydrate digestion and fermentation, which may contribute to a decrease in SCFA production [17]. Given that bacterial abundance of the Lachnospiraceae family was altered based on level of Zn adequacy and the ZSI found bacteria of this family to have significant predictive power, future studies should target Lachnospiraceae for further refinement of the ZSI. Future clinical trials should take into account the combination of the LA:DGLA level in red blood cells, $\Delta 6$-desaturase gene expression in red blood cells, and fecal microbial abundance of bacteria in the Lachnospiraceae family for accurate assessment of Zn physiological status.

Our three-pillar ZSI concept demonstrated that the LA:DGLA ratio, Zn-related gene expression, and microbiome analyses were predictive factors of $\mathrm{Zn}$ status; however, our prediction formula was obtained using data from in vivo studies and a relatively small sample size $(n=59)$. It is possible these parameters may be part of a larger set of predictive parameters, and future research may further elucidate which parameters have the highest predictive power. Given that each experiment will yield different LA:DGLA ratios, gene expression levels, and microbiome profile, a calibration tool will need to be built into the model. For example, for subject A in example 3, shown in Table 6, the 80th percentile of LA:DGLA ratio is approximately 70, but if another subject from another study has an LA:DGLA of 50, we need to know what this value would translate to if the subject were analyzed with a different experimental batch. Microbiome profiles may differ between target populations $[65,66]$, where there may be differences in bacterial abundance associated with differential $\mathrm{Zn}$ status between specific target populations. Additionally, there is future potential for minimizing the cost of each test. For example, if the observed LA:DGLA ratio is sufficiently high (or low) based on our predictive formula to conclude the $\mathrm{Zn}$ adequacy level with high probability, then further gene expression or microbiome analyses may not be necessary. As shown in example 3, the combination of the LA:DGLA level and $\Delta 6$-desaturase and ZIP9 expression had sufficient predictive power where fecal microbial profiling was not included. This demonstrates the versatility and flexibility of the ZSI concept. After further refinement of the ZSI prediction model utilizing data from future studies, a baseline for calibration can be built to standardize for potential batch effects associated with differences in experimental dates, sites, and/or target populations.

Altogether, the ZSI was shown to be a highly sensitive Zn status predictor, predictive of various degrees of Zn adequacy (or inadequacy). The current ZSI is a prototype and will evolve as more data emerge. Further, our eventual goal is to use the ZSI to predict Zn physiological status at both the individual and population levels. Utilization of the ZSI will ultimately lead to more precise assessment of the effects of dietary $\mathrm{Zn}$ interventions and medical outcomes. 


\section{Conclusions}

We present the ZSI prototype as a strategy to better understand Zn nutrition in the context of a complete diet. Our evidence demonstrates the potential of the ZSI as an accurate predictor of $\mathrm{Zn}$ physiological status that is responsive to dietary $\mathrm{Zn}$ changes. The ZSI can be used to assess the efficacy of dietary interventions in target populations, for example, in the context of the assessment of Zn-biofortified staple food crops, relevant dietary supplements or fortifiers, and other nutritional approaches that are used to improve $\mathrm{Zn}$ status. Zn deficiency is often missed due to the inflammation status of the subject (and when serum/plasma $\mathrm{Zn}$ concentrations are used as $\mathrm{Zn}$ physiological status), which is especially pertinent in vulnerable populations. Thus, the development and usage of the ZSI is highly relevant for the accurate measurement of $\mathrm{Zn}$ physiological status. Further studies are warranted to further train and refine the ZSI model.

Author Contributions: Conceptualization, H.B. and E.T.; methodology, J.C., H.B., and E.T.; formal analysis, H.B.; writing-original draft preparation, J.C. and E.T.; writing-review and editing, J.C., H.B., and E.T.; supervision, H.B. and E.T.; project administration, E.T. All authors have read and agreed to the published version of the manuscript.

Funding: This research received no external funding.

Institutional Review Board Statement: The animal protocol used in this study was conducted according to the guidelines of the Declaration of Helsinki and approved by the Cornell University Institutional Animal Care and Use Committee by ethic approval code 2020-0077.

Informed Consent Statement: Not applicable.

Conflicts of Interest: The authors declare no conflict of interest.

\section{References}

1. Wessells, K.R.; Brown, K.H. Estimating the global prevalence of zinc deficiency: Results based on zinc availability in national food supplies and the prevalence of stunting. PLoS ONE 2012, 7, e50568. [CrossRef]

2. Maret, W.; Sandstead, H.H. Zinc requirements and the risks and benefits of zinc supplementation. J. Trace Elem. Med. Biol. 2006, 20,3-18. [CrossRef] [PubMed]

3. Andreini, C.; Banci, L.; Bertini, I.; Rosato, A. Counting the Zinc-Proteins Encoded in the Human Genome. J. Proteome Res. 2005, 5, 196-291. [CrossRef] [PubMed]

4. Gaither, L.; Eide, D.J. Eukaryotic zinc transporters and their regulation. BioMetals 2001, 14, 65-84. [CrossRef] [PubMed]

5. Frederickson, C.J.; Koh, J.Y.; Bush, A.I. The neurobiology of zinc in health and disease. Nat. Rev. Neurosci 2005, 6, 449-462. [CrossRef]

6. Maares, M.; Haase, H. A Guide to Human Zinc Absorption: General Overview and Recent Advances of In Vitro Intestinal Models. Nutrients 2020, 12, 762. [CrossRef]

7. Black, R.E.; Sazawal, S. Zinc and childhood infectious disease morbidity and mortality. Br. J. Nutr. 2001, 85 (Suppl. 2), S125-S129. [CrossRef]

8. Lowe, N.M.; Fekete, K.; Decsi, T. Methods of assessment of zinc status in humans: A systematic review. Am. J. Clin. Nutr. 2009, 89, 2040S-2051S. [CrossRef]

9. WHO/FAO. Vitamin and Mineral Requirements in Human Nutrition; WHO: Geneva, Switzerland, 2004.

10. Ezzati, M.; Lopez, A.D.; Rodgers, A.A.; Murray, C.J.L. Comparative Quantification of Health Risks: Global and Regional Burden of Disease Attributable to Selected Major Risk Factors; World Health Organization: Geneva, Switzerland, 2004.

11. Lowe, N.M. Assessing zinc in humans. Curr. Opin. Clin. Nutr. Metab. Care. 2016, 19, 321-327. [CrossRef]

12. King, J.C.; Brown, K.H.; Gibson, R.S.; Krebs, N.F.; Lowe, N.M.; Siekmann, J.H.; Raiten, D.J. Biomarkers of Nutrition for Development (BOND)-Zinc Review. J. Nutr. 2015, 146, 858S-885S. [CrossRef]

13. Reed, S.; Qin, X.; Ran-Ressler, R.; Brenna, J.T.; Glahn, R.P.; Tako, E. Dietary zinc deficiency affects blood linoleic acid: Dihomogamma-linolenic acid (LA:DGLA) ratio; a sensitive physiological marker of zinc status in vivo (Gallus gallus). Nutrients 2014, 6, 1164-1180. [CrossRef] [PubMed]

14. Tako, E.; Ferket, P.R.; Uni, Z. Changes in chicken intestinal zinc exporter mRNA expression and small intestinal functionality following intra-amniotic zinc-methionine administration. J. Nutr. Biochem. 2005, 16, 339-346. [CrossRef] [PubMed]

15. Andree, K.; Kim, J.; Kirschke, C.P.; J., G.; H., P.; Joung, H.; Woodhouse, L.; King, J.C.; Huang, L. Investigation of Lymphocyte Gene Expression for Use as Biomarkers for Zinc Status in Humans. J. Nutr. 2004, 134, 1716-1723. [CrossRef]

16. Carboni, J.; Reed, S.; Kolba, N.; Eshel, A.; Koren, O.; Tako, E. Alterations in the Intestinal Morphology, Gut Microbiota, and Trace Mineral Status Following Intra-Amniotic Administration (Gallus gallus) of Teff (Eragrostis tef) Seed Extracts. Nutrients 2020, 12, 3020. [CrossRef] 
17. Reed, S.; Neuman, H.; Moscovich, S.; Glahn, R.P.; Koren, O.; Tako, E. Chronic Zinc Deficiency Alters Chick Gut Microbiota Composition and Function. Nutrients 2015, 7, 9768-9784. [CrossRef] [PubMed]

18. Reed, S.; Knez, M.; Uzan, A.; Stangoulis, J.C.R.; Glahn, R.P.; Koren, O.; Tako, E. Alterations in the Gut (Gallus gallus) Microbiota Following the Consumption of Zinc Biofortified Wheat (Triticum aestivum)-Based Diet. J. Agric. Food Chem 2018, 66, 6291-6299. [CrossRef]

19. Juste Contin Gomes, M.; Stampini Duarte Martino, H.; Tako, E. Effects of Iron and Zinc Biofortified Foods on Gut Microbiota In Vivo (Gallus gallus): A Systematic Review. Nutrients 2021, 13, 189. [CrossRef]

20. Beasley, J.T.; Johnson, A.A.T.; Kolba, N.; Bonneau, J.P.; Glahn, R.P.; Ozeri, L.; Koren, O.; Tako, E. Nicotianamine-chelated iron positively affects iron status, intestinal morphology and microbial populations in vivo (Gallus gallus). Sci. Rep. 2020, $10,2297$. [CrossRef]

21. Knez, M.; Tako, E.; Glahn, R.P.; Kolba, N.; de Courcy-Ireland, E.; Stangoulis, J.C.R. Linoleic Acid:Dihomo-gamma-Linolenic Acid Ratio Predicts the Efficacy of Zn-Biofortified Wheat in Chicken (Gallus gallus). J. Agric. Food Chem. 2018, 66, 1394-1400. [CrossRef]

22. Hou, T.; Tako, E. The In Ovo Feeding Administration (Gallus Gallus)-An Emerging In Vivo Approach to Assess Bioactive Compounds with Potential Nutritional Benefits. Nutrients 2018, 10, 418. [CrossRef]

23. Dias, D.M.; Costa, N.M.B.; Nutti, M.R.; Tako, E.; Martino, H.S.D. Advantages and limitations of in vitro and in vivo methods of iron and zinc bioavailability evaluation in the assessment of biofortification program effectiveness. Crit. Rev. Food Sci. Nutr. 2018, 58, 2136-2146. [CrossRef]

24. Mahler, G.J.; Esch, M.B.; Tako, E.; Southard, T.L.; Archer, S.D.; Glahn, R.P.; Shuler, M.L. Oral exposure to polystyrene nanoparticles affects iron absorption. Nat. Nanotechnol. 2012, 7, 264-271. [CrossRef]

25. Dias, D.M.; Kolba, N.; Hart, J.J.; Ma, M.; Sha, S.T.; Lakshmanan, N.; Nutti, M.R.; Martino, H.S.D.; Glahn, R.P.; Tako, E. Soluble extracts from carioca beans (Phaseolus vulgaris L.) affect the gut microbiota and iron related brush border membrane protein expression in vivo (Gallus gallus). Food Res. Int 2019, 123, 172-180. [CrossRef]

26. Tako, E.; Glahn, R.P.; Knez, M.; Stangoulis, J.C.R. The effect of wheat prebiotics on the gut bacterial population and iron status of iron deficient broiler chickens. Nutr. J. 2014, 13, 1-10. [CrossRef]

27. Consortium, I.C.G.S. Sequence and comparative analysis of the chicken genome provide unique perspectives on vertebrate evolution. Nature 2004, 432, 695-777.

28. Hou, T.; Kolba, N.; Glahn, R.P.; Tako, E. Intra-Amniotic Administration (Gallus gallus) of Cicer arietinum and Lens culinaris Prebiotics Extracts and Duck Egg White Peptides Affects Calcium Status and Intestinal Functionality. Nutrients 2017, 9, 785. [CrossRef] [PubMed]

29. Reed, S.; Neuman, H.; Glahn, R.P.; Koren, O.; Tako, E. Characterizing the gut (Gallus gallus) microbiota following the consumption of an iron biofortified Rwandan cream seeded carioca (Phaseolus Vulgaris L.) bean-based diet. PLoS ONE 2017, 12, e0182431. [CrossRef]

30. Decuypere, E.; Michels, H. Incubation temperature as a management tool: A review. World's Poult. Sci. Assoc. 1992, 48, 28-38. [CrossRef]

31. Council, Nutrient Requirement. Nutrient Requirements of Poultry; National Academies Press: Washington, DC, USA, 1994; Volume 42, pp. 57-63.

32. Liong, E.M.; McDonald, C.M.; Suh, J.; Westcott, J.L.; Wong, C.P.; Signorell, C.; King, J.C. Zinc-Biofortified Wheat Intake and Zinc Status Biomarkers in Men: Randomized Controlled Trial. J. Nutr. 2021, 151, 1817-1823. [CrossRef]

33. Monteiro, J.P.; Fuzo, C.A.; Ued, F.V.; Kaput, J. Dietary patterns related to zinc and polyunsaturated fatty acids intake are associated with serum linoleic/dihomo-gamma-linolenic ratio in NHANES males and females. Sci. Rep. 2021, 11, 12215. [CrossRef]

34. Chimhashu, T.; Malan, L.; Baumgartner, J.; van Jaarsveld, P.J.; Galetti, V.; Moretti, D.; Smuts, C.M.; Zimmermann, M.B. Sensitivity of fatty acid desaturation and elongation to plasma zinc concentration: A randomised controlled trial in Beninese children. Br. J. Nutr. 2018, 119, 610-619. [CrossRef]

35. Knez, M.; Stangoulis, J.C.R.; Zec, M.; Debeljak-Martacic, J.; Pavlovic, Z.; Gurinovic, M.; Glibetic, M. An initial evaluation of newly proposed biomarker of zinc status in humans-linoleic acid: Dihomo-gamma-linolenic acid (LA:DGLA) ratio. Clin. Nutr. ESPEN 2016, 15, 85-92. [CrossRef] [PubMed]

36. Wang, X.; Kolba, N.; Liang, J.; Tako, E. Alterations in gut microflora populations and brush border functionality following intra-amniotic administration (Gallus gallus) of wheat bran prebiotic extracts. Food Funct. 2019, 10, 4834-4843. [CrossRef] [PubMed]

37. Martino, H.S.D.; Kolba, N.; Tako, E. Yacon (Smallanthus sonchifolius) flour soluble extract improve intestinal bacterial populations, brush border membrane functionality and morphology in vivo (Gallus gallus). Food Res. Int. 2020, 137, 109705. [CrossRef] [PubMed]

38. Knez, M.; Pantovic, A.; Zekovic, M.; Pavlovic, Z.; Glibetic, M.; Zec, M. Is There a Link between Zinc Intake and Status with Plasma Fatty Acid Profile and Desaturase Activities in Dyslipidemic Subjects? Nutrients 2019, 12, 93. [CrossRef] [PubMed]

39. Andreini, C.; Banci, L.; Bertini, I.; Rosato, A. Zinc through the Three Domains of Life. J. Proteome Res. 2006, 5, 3173-3178. [CrossRef] 
40. Burrell, A.L.; Dozier, W.A., 3rd; Davis, A.J.; Compton, M.M.; Freeman, M.E.; Vendrell, P.F.; Ward, T.L. Responses of broilers to dietary zinc concentrations and sources in relation to environmental implications. Br. Poult Sci. 2004, 45, 255-263. [CrossRef] [PubMed]

41. King, J.C. Yet Again, Serum Zinc Concentrations Are Unrelated to Zinc Intakes. J. Nutr. 2018, 148, 1399-1401. [CrossRef]

42. Harris, W.S. Assessing fatty acid biostatus: Red blood cells or plasma? Lipid Technol. 2013, 25, 179-181. [CrossRef]

43. Smith, H.E.; Ryan, K.N.; Stephenson, K.B.; Westcott, C.; Thakwalakwa, C.; Maleta, K.; Cheng, J.Y.; Brenna, J.T.; Shulman, R.J.; Trehan, I.; et al. Multiple micronutrient supplementation transiently ameliorates environmental enteropathy in Malawian children aged 12-35 months in a randomized controlled clinical trial. J. Nutr. 2014, 144, 2059-2065. [CrossRef]

44. Takagishi, T.; Hara, T.; Fukada, T. Recent Advances in the Role of SLC39A/ZIP Zinc Transporters In Vivo. Int J. Mol. Sci. 2017, 18, 2708. [CrossRef]

45. Kimura, T.; Kambe, T. The Functions of Metallothionein and ZIP and ZnT Transporters: An Overview and Perspective. Int. J. Mol. Sci. 2016, 17, 336. [CrossRef]

46. Huang, L.; Tepaamorndech, S. The SLC30 family of zinc transporters-A review of current understanding of their biological and pathophysiological roles. Mol. Asp. Med. 2013, 34, 548-560. [CrossRef]

47. Jeong, J.; Eide, D.J. The SLC39 family of zinc transporters. Mol. Asp. Med. 2013, 34, 612-619. [CrossRef]

48. Geiser, J.; Venken, K.J.; De Lisle, R.C.; Andrews, G.K. A mouse model of acrodermatitis enteropathica: Loss of intestine zinc transporter ZIP4 (Slc39a4) disrupts the stem cell niche and intestine integrity. PLoS Genet. 2012, 8, e1002766. [CrossRef] [PubMed]

49. Hashimoto, A.; Nakagawa, M.; Tsujimura, N.; Miyazaki, S.; Kizu, K.; Goto, T.; Komatsu, Y.; Matsunaga, A.; Shirakawa, H.; Narita, H.; et al. Properties of Zip4 accumulation during zinc deficiency and its usefulness to evaluate zinc status: A study of the effects of zinc deficiency during lactation. Am. J. Physiol. Regul. Integr. Comp. Physiol. 2016, 310, R459-R468. [CrossRef] [PubMed]

50. Koletzko, B.; Abiodun, P.O.; Laryea, M.D.; Bremer, H.J. Fatty acid composition of plasma lipids in Nigerian children with protein-energy malnutrition. Eur. J. Pediatr. 1986, 145, 109-115. [CrossRef] [PubMed]

51. Ayala, S.; Brenner, R.R. Dietary Zinc Deficiency and Fatty Acid Metabolism in Rats. Acta Physiol. Lat. Am. 1983, 33, 193-204. [PubMed]

52. Macfarlane, G.T.; Macfarlane, S. Bacteria, colonic fermentation, and gastrointestinal health. J. AOAC Int. 2012, 95, 50-60 [CrossRef]

53. Coudray, C.; Feillet-Coudray, C.; Gueux, E.; Masur, A.; Rayssiguier, Y. Dietary Inulin Intake and Age Can Affect Intestinal Absorption of Zinc and Copper in Rats. J. Nutr. 2006, 136, 117-122. [CrossRef]

54. La Reau, A.J.; Suen, G. The Ruminococci: Key symbionts of the gut ecosystem. J. Microbiol. 2018, 56, 199-208. [CrossRef]

55. Chinda, D.; Nakaji, S.; Fukuda, S.; Sakamoto, J.; Shimoyama, T.; Nakamura, T.; Fujisawa, T.; Terada, A.; Sugawara, K. The Fermentation of Different Dietary Fibers Is Associated with Fecal Clostridia Levels in Men. J. Nutr. 2004, 134, $1881-1886$. [CrossRef]

56. Vacca, M.; Celano, G.; Calabrese, F.M.; Portincasa, P.; Gobbetti, M.; De Angelis, M. The Controversial Role of Human Gut Lachnospiraceae. Microorganisms 2020, 8, 573. [CrossRef]

57. Sorbara, M.T.; Littmann, E.R.; Fontana, E.; Moody, T.U.; Kohout, C.E.; Gjonbalaj, M.; Eaton, V.; Seok, R.; Leiner, I.M.; Pamer, E.G. Functional and Genomic Variation between Human-Derived Isolates of Lachnospiraceae Reveals Inter- and Intra-Species Diversity. Cell Host Microbe 2020, 28, 134-146.e134. [CrossRef]

58. Sheridan, P.; Martin, J.C.; Lawley, T.D.; Browne, H.; Harris, H.M.B.; Bernalier-Donadille, A.; Duncan, S.; O'Toole, P.W.; Scott, K.P.; Flint, H.J. Polysaccharide utilization loci and nutritional specialization in a dominant group of butyrate-producing human colonic Firmicutes. Microb. Genom. 2016, 2, e000043. [CrossRef] [PubMed]

59. Edens, F.W.; Parkhurst, C.R.; Casas, I.A.; Dobrogosz, W.J. Principles of ex ovo competitive exclusion and in ovo administration of Lactobacillus reuteri. Poult. Sci. 1997, 76, 179-196. [CrossRef] [PubMed]

60. Mengheri, E.N.; Vignolini, F.; Pesenti, M.; Brandi, G.; Biavati, B. Bifidobacterium animalis Protects Intestine from Damage Induced by Zinc Deficiency in Rats. J. Nutr. 1997, 129, 2251-2257. [CrossRef]

61. Roselli, M.F.A.; Garaguso, I.; Britti, M.S.; Mengheri, E. Zinc Oxide Protects Cultured Enterocytes from the Damage Induced by Escherichia coli. J. Nutr. 2003, 133, 4077-4082. [CrossRef] [PubMed]

62. King, J.C. Zinc: An essential but elusive nutrient. Am. J. Clin. Nutr. 2011, 94, 679S-684S. [CrossRef] [PubMed]

63. Wood, R.J. Assessment of Marginal Zinc Status in Humans. J. Nutr. 2000, 130, 1350S-1354S. [CrossRef]

64. Knez, M.; Stangoulis, J.C.R.; Glibetic, M.; Tako, E. The Linoleic Acid: Dihomo-gamma-Linolenic Acid Ratio (LA:DGLA)—An Emerging Biomarker of Zn Status. Nutrients 2017, 9, 825. [CrossRef] [PubMed]

65. Biddle, A.; Stewart, L.; Blanchard, J.; Leschine, S. Untangling the Genetic Basis of Fibrolytic Specialization by Lachnospiraceae and Ruminococcaceae in Diverse Gut Communities. Diversity 2013, 5, 627-640. [CrossRef]

66. Yatsunenko, T.; Rey, F.E.; Manary, M.J.; Trehan, I.; Dominguez-Bello, M.G.; Contreras, M.; Magris, M.; Hidalgo, G.; Baldassano, R.N.; Anokhin, A.P.; et al. Human gut microbiome viewed across age and geography. Nature 2012, 486, 222-227. [CrossRef] [PubMed] 